Research Article

\title{
Vibration Characteristics of an Industrial-Scale Flip-Flow Screen with Crank-Link Structure and Parameters Optimization
}

\author{
Hongxi Li $\mathbb{D}^{1}{ }^{1}$ Chusheng Liu, ${ }^{1}$ Ling Shen, ${ }^{2}$ and Lala Zhao ${ }^{1}$ \\ ${ }^{1}$ School of Mechatronic Engineering, China University of Mining and Technology, Xuzhou, Jiangsu 221116, China \\ ${ }^{2}$ School of Materials Science and Physics, China University of Mining and Technology, Xuzhou, Jiangsu 221116, China \\ Correspondence should be addressed to Hongxi Li; lihongxi@cumt.edu.cn
}

Received 7 April 2021; Accepted 17 September 2021; Published 27 September 2021

Academic Editor: Franck Poisson

Copyright (c) 2021 Hongxi Li et al. This is an open access article distributed under the Creative Commons Attribution License, which permits unrestricted use, distribution, and reproduction in any medium, provided the original work is properly cited.

Flip-flow screens are increasingly used in the processing of fine wet coal. In this work, the vibration characteristics of an industrialscale flip-flow screen with crank-link structure (FFSCLS) were investigated theoretically and experimentally. An improved kinematic model of FFSCLS was proposed and experiments are carried out to verify the reasonability. The effects of the key parameters of the eccentricity of the crankshaft, the rotational speed of the crankshaft, and the tension length of the screen surface on the vibration characteristics of the screen were investigated parametrically. The results show that the kinematic model can describe the vibration characteristics of screen perfectly with the maximum error between the theoretical and experimental results being within $6.96 \%$. Moreover, the key parameters of the eccentricity of the crankshaft, the rotational speed of the crankshaft, and the tension length of the screen surface have significant effects on the vibrations of the screen body and screen surface. These parameters should be optimized to achieve maximum screening performance of the FFSCLS. This work should be useful for optimal design and efficient operation of the flip-flow screen.

\section{Introduction}

Screening plays a key role in the classification, medium draining, product dehydration, and desliming of coal [1-3]. In recent years, the dry deep screening of moist and fine minerals, which can simplify the cleaning process, has become increasingly essential for coal classification [4-6]. Due to insufficient vibration strength, traditional vibration screens may encounter low screening efficiency when processing moist materials [7-9] and blocking of screen apertures by near-mesh particles [10-12]. However, the flipflow screens employed in the coal preparation industry have great advantages over traditional vibrating screens in the enhancement of screen surface vibration strength and few blockages of the apertures [13-16].

Generally, the vibration mass will increase significantly with the increase of the screen surface area and the screening capacity [17]. Consequently, the flip-flow screens bear an alternating loading with heavy amplitude and high frequency. Moreover, the flip-flow screens suffer from an exciting force generated by the vibration of the two screen boxes and an impact from the particulate materials, both of which could lead to spring fracture [18], and polyurethane surface rupture $[19,20]$. Thus, a fundamental research of the effects about geometrical and operational conditions on the flip-flow screen vibration characteristics should be performed, which could be useful for optimum design and control of the flip-flow screen.

To date, there are increasing researches on the flip-flow screen in the literature. In order to fully understand the working mechanism of the flip-flow screen and optimize the relationship between screening efficiency, production capacity, and energy consumption, parameters of geometric, technological, and kinematics have been considered [21]. The basic working principle of the screen, the midpoint motion law of the flip-flow screen surface, and the screen surface-particle trajectory were investigated by considering the screen surface as a simply supported beam [22]. Recently, the vertical deformation and acceleration of a flip-flow screen surface were investigated experimentally [23]. Wu 
et al. [24] presented a method of two-way coupling relationship between particles and screen surfaces and results indicate that the equivalent method of approximate flexibility was effective. To investigate the application of polyurethane screen deck in linear vibrating screen, Zhang and Wang [25] built the kinematic model of polyurethane screen deck in sieving and obtained the optimization curve between the height and width of the grizzly bar.

The vibration and geometric characteristics of the screen surface play an important role in the stratification, migration, and penetration of particles, both of which will affect the screening performance and production capacity. Furthermore, besides the effects of the screen surface, the vibration of the screen body was also investigated extensively. Baragetti and Villa [26] presented an innovative design strategy validated using full-scale experimental tests for the optimization of the kinematic performances and the structural loads of heavy loaded vibrating screens. To obtain the inherent characteristic and operating condition parameters of a large vibrating screen, Zhang et al. [27] predicted the physical characteristics from its scale-down model and provided an effective method for structural optimization and substructure coupling analysis.

The flip-flow screen with crank-link structure (FFSCLS) is an essential technology for separation of fine moist coal which can significantly improve the economic benefits of the coal preparation plant [28]. Nevertheless, based on the above review, only a few have focused on the fundamental theories of FFSCLS. Parameters such as crankshaft eccentricity, crankshaft rotational speed, and tension length of the screen surface all play important roles on the vibration and screening performance of this flip-flow screen, which need to be studied further. In this work, a kinematic model of an industrial-scale flip-flow screen with crank-link structure will be developed. The vibration characteristic of the flipflow screen will be studied and the reasonability will be verified by experiment. Besides, the effects of the crankshaft eccentricity and the crankshaft rotational speed and the tension length of the screen surface on the vibration characteristics of the flip-flow screen will be investigated parametrically. The results obtained in this work should be beneficial for the understanding of the combined effects of parameters and could provide essential references for optimal design and efficient operation of the flip-flow screen.

\section{Model Constructions}

The investigated FFSCLS used in Lijiahao coal preparation plant of China is shown schematically in Figure 1. The fixed box is supported by rubber springs and steel springs on the base. The floating box is connected to the fixed box by one end of the guide spring whose other end is mounted on the fixed box. The whole screen surface is composed of 28 panels. Two ends of each screen panel are fixed on the fixed box beam and the adjacent floating box beam. The driving system including the drive motor and crankshaft is installed on the fixed box headend with high-strength bolts. The link connects the floating box and crankshaft. Moreover, the vibration of the FFSCLS is shown in Figure 2.
When the crankshaft is rotated by the driving motor, staggered motion occurs between the fixed and the floating boxes, which causes the screen surface to slacken and stretch periodically [29]. The moving screen surface allowing particles to be separated into undersize through the apertures and oversize discharged from the end of the deck, respectively.

2.1. Kinematic Model of the FFSCLS Screen Body. The vibration parameters such as exciting force, displacement, velocity, acceleration, and natural frequency can be obtained from the kinematic model of the FFSCLS. As natural characteristics of the screen, these vibration parameters provide important reference for evaluating the design rationality and operational reliability of the FFSCLS. The kinematic model of the FFSCLS screen body was established, as shown in Figure 3. During the screening process of FFSCLS, the crankshaft is driven by the motor to make uniform circular motion while the floating box and fixed box make a similar linear reciprocating motion. To investigate the vibration of the flip-flow screen, an absolute coordinate frame $O X Y$ was established. The $X$-direction is along the screen surface. Based on the working principle, the guide spring, link, and crankshaft are simplified and treated equivalently, where $e$ is the eccentricity of the crankshaft, $L_{e}$ is the length of the link, $L_{r}$ is the length of the guide spring, and $\varphi_{r}$ is the pendulum angle of the guide spring.

When the crankshaft rotates, the displacement of the floating box is

$$
\left\{\begin{array}{l}
\Delta X=e \cos \theta+\sqrt{L_{e}^{2}-e^{2} \sin ^{2} \theta}-L_{e} \\
\Delta Y=L_{r}\left(1-\cos \varphi_{r}\right)
\end{array}\right.
$$

where $\theta$ is the crankshaft rotational angle; $\Delta X$ and $\Delta Y$ are the displacements of the floating box relative to the fixed box along the $X$ - and $Y$-directions, respectively. $\Delta X$ and $\Delta Y$ can also be written as

$$
\left\{\begin{array}{l}
\Delta X=X_{1}-X_{2} \\
\Delta Y=Y_{1}-Y_{2}
\end{array}\right.
$$

where $\left(X_{1}, Y_{1}\right)$ and $\left(X_{2}, Y_{2}\right)$ are the displacements of the floating box and fixed box relative to the absolute coordinate frame $O X Y$, respectively.

The rotation angle of the crankshaft $\theta$ can be obtained through

$$
\theta=\omega t
$$

where $\omega$ is the rotational speed of the crankshaft. It is noticed that $e$ is much smaller than $L_{e}$ and $L_{r}$, thus the displacement of the floating box can be simplified as

$$
\left\{\begin{array}{l}
\Delta X=e \cos \omega t \\
\Delta Y=0
\end{array}\right.
$$

By taking the first and second derivatives of equation (4) to time $t$, the floating box velocity and acceleration relative to the fixed box can be obtained as follows: 


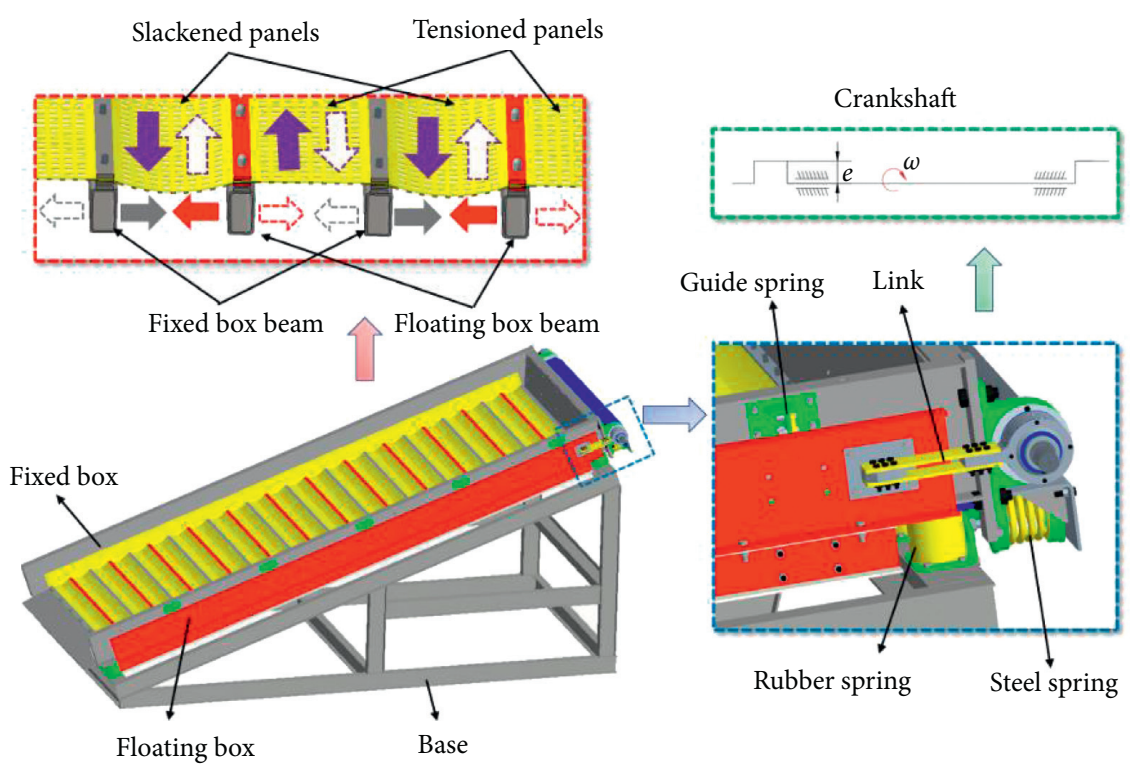

FIgURE 1: The structure of the industrial-scale FFSCLS.

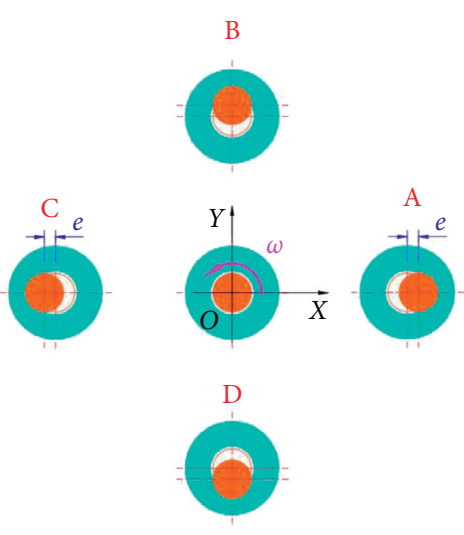

(a)

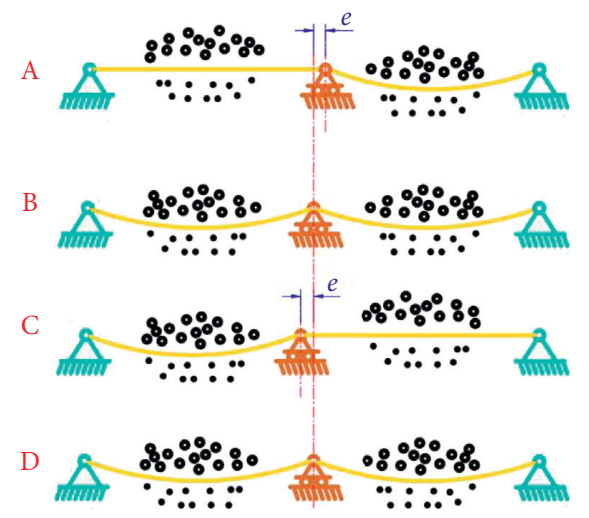

(b)

Figure 2: The vibration of the FFSCLS.

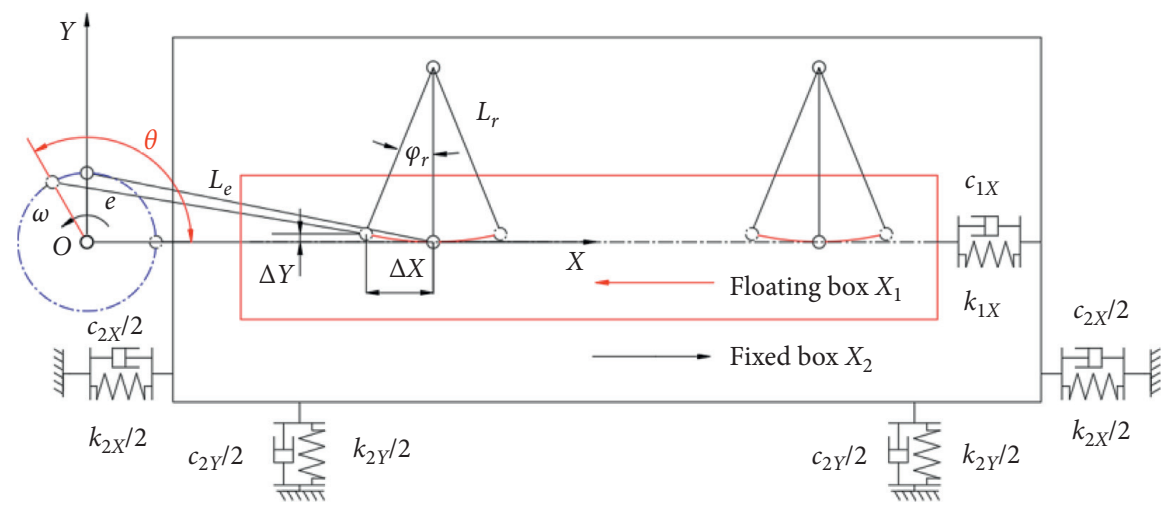

FIgURE 3: Kinematic model of the FFSCLS screen body. 


$$
\left\{\begin{array}{l}
\Delta \dot{X}=-e \omega \sin \omega t \\
\Delta \dot{Y}=0 \\
\Delta \ddot{X}=-e \omega^{2} \cos \omega t \\
\Delta \ddot{Y}=0
\end{array}\right.
$$

where $\Delta \dot{X}(\Delta \dot{X})$ and $\Delta \dot{Y}(\Delta \dot{Y})$ are the velocities (accelerations) of the floating box along the $X$ - and $Y$-directions relative to the fixed box, respectively.

When the crankshaft rotates, the exciting force $F$ generated by the reciprocating motion of the floating box is harmonic force. The value of exciting force $F$ in $X$ - and $Y$ directions $\left(F_{X}, F_{Y}\right)$ can be obtained through

$$
\left\{\begin{array}{l}
F_{X}=m_{1} \Delta \ddot{X}=-m_{1} e \omega^{2} \cos \omega t, \\
F_{Y}=m_{1} \Delta \ddot{Y}=0
\end{array}\right.
$$

where $m_{1}$ is the mass of the floating box.

Then, the kinematic equation of the screen body can be written as

$$
\left\{\begin{array}{l}
\left(m_{1}+m_{2}\right) \ddot{X}_{2}+c_{2 X} \dot{X}_{2}+k_{2 X} X_{2}=m_{1} e \omega^{2} \cos \omega t \\
\left(m_{1}+m_{2}\right) \ddot{Y}_{2}+c_{2 Y} \dot{Y}_{2}+k_{2 Y} Y_{2}=0,
\end{array}\right.
$$

where $m_{2}$ is the mass of the fixed box; $\dot{X}_{2}\left(\ddot{X}_{2}\right)$ and $\dot{Y}_{2}\left(\ddot{Y}_{2}\right)$ are the velocities (accelerations) of the fixed box relative to the absolute coordinate frame $O X Y$ along the $X$ - and $Y$ directions, respectively. $k_{2 X}\left(c_{2 X}\right)$ and $k_{2 Y}\left(c_{2 Y}\right)$ are the equivalent springs stiffness (damping) coefficients (rubber springs and vibration isolation springs) along the $X$ - and $Y$ directions, respectively.

Due to the relatively small damping force, the damping effect can be ignored in the present study. Therefore, the displacement of the fixed box in $X$ - and $Y$-directions $\left(X_{2}, Y_{2}\right)$ can be obtained by the following forms:

$$
\left\{\begin{array}{l}
X_{2}=A_{2 X} \cos \omega t \\
Y_{2}=0
\end{array}\right.
$$

where $A_{2 X}$ is the vibration amplitude of the fixed box. Thus, velocity and acceleration can be calculated through

$$
\left\{\begin{array}{l}
\dot{X}_{2}=-A_{2 X} \omega \sin \omega t \\
\ddot{X}_{2}=-A_{2 X} \omega^{2} \cos \omega t \\
\dot{Y}=0 \\
\ddot{Y}_{2}=0
\end{array}\right.
$$

Substituting equations (8) and (9) into equation (7), $A_{2 X}$ can be obtained:

$$
A_{2 X}=\frac{m_{1} e \omega^{2}}{k_{2 X}-\left(m_{1}+m_{2}\right) \omega^{2}} .
$$

Thus, by ignoring the motion in the $Y$-direction, the displacement, velocity, and acceleration of the fixed box relative to the absolute coordinate frame OXY can be calculated through

$$
\left\{\begin{array}{l}
X_{2}=\frac{m_{1} e \omega^{2}}{k_{2 X}-\left(m_{1}+m_{2}\right) \omega^{2}} \cos \omega t, \\
\dot{X}_{2}=-\frac{m_{1} e \omega^{3}}{k_{2 X}-\left(m_{1}+m_{2}\right) \omega^{2}} \sin \omega t, \\
\ddot{X}_{2}=-\frac{m_{1} e \omega^{4}}{k_{2 X}-\left(m_{1}+m_{2}\right) \omega^{2}} \cos \omega t .
\end{array}\right.
$$

Substituting equations (4), (5), and (11) into equation (2), the displacements $\left(X_{1}, Y_{1}\right)$ of the floating box can be obtained as follows:

$$
\left\{\begin{array}{l}
X_{1}=e \cos \omega t+\frac{m_{1} \omega^{2}}{k_{2 X}-\left(m_{1}+m_{2}\right) \omega^{2}} e \cos \omega t \\
Y_{1}=0
\end{array}\right.
$$

Taking the first and second derivatives of equation (12), the floating box velocity and acceleration with the coordinate frame $O X Y$ can be obtained as follows:

$$
\left\{\begin{array}{l}
\dot{X}_{1}=-\left(1+\frac{m_{1} \omega^{2}}{k_{2 X}-\left(m_{1}+m_{2}\right) \omega^{2}}\right) e \omega \sin \omega t, \\
\ddot{X}_{1}=-\left(1+\frac{m_{1} \omega^{2}}{k_{2 X}-\left(m_{1}+m_{2}\right) \omega^{2}}\right) e \omega^{2} \cos \omega t, \\
\dot{Y}_{1}=0 \\
\ddot{Y}_{1}=0
\end{array}\right.
$$

where $\dot{X}_{1}\left(\ddot{X}_{1}\right)$ and $\dot{Y}_{1}\left(\ddot{Y}_{1}\right)$ are the velocities (accelerations) of the floating box along the $X$ - and $Y$-directions, respectively. Thus, the displacement, velocity, and acceleration of the floating box relative to the absolute coordinate frame OXY can be calculated through

$$
\left\{\begin{array}{l}
X_{1}=\frac{k_{2 X}-m_{2} \omega^{2}}{k_{2 X}-\left(m_{1}+m_{2}\right) \omega^{2}} e \cos \omega t \\
\dot{X}_{1}=-\frac{k_{2 X}-m_{2} \omega^{2}}{k_{2 X}-\left(m_{1}+m_{2}\right) \omega^{2}} e \omega \sin \omega t, \\
\ddot{X}_{1}=-\frac{k_{2 X}-m_{2} \omega^{2}}{k_{2 X}-\left(m_{1}+m_{2}\right) \omega^{2}} e \omega^{2} \cos \omega t .
\end{array}\right.
$$

The vibration amplitude of the floating box $A_{1 X}$ can be written as follows:

$$
A_{1 X}=\frac{k_{2 X}-m_{2} \omega^{2}}{k_{2 X}-\left(m_{1}+m_{2}\right) \omega^{2}} e .
$$


Based on equations (11) and (14), when the denominator is 0 , the natural angular frequency $\omega_{\mathrm{n} X}$ and the natural frequencies $f_{\mathrm{n} X}$ of the vibration system in $X$-direction can be calculated:

$$
\left\{\begin{array}{l}
\omega_{n X}=\sqrt{\frac{k_{2 X}}{\left(m_{1}+m_{2}\right)}}, \\
f_{n X}=\frac{1}{2 \pi} \sqrt{\frac{k_{2 X}}{\left(m_{1}+m_{2}\right)}} .
\end{array}\right.
$$

2.2. Kinematic Model of the Screen Surface. Based on the working principle of FFSCLS shown in Figure 1, the vibration motion of the screen surface mainly consists of two parts of motions: the relative motion induced by the floating and fixed box beam that paralleled the screen surface. The other is caused by relaxation and tension of the elastic screen surface, whose direction is perpendicular to the screen surface. In this section, the deflection of the screen surface is modelled based on the three-tangent arcs theory [28]. The modelling detail is given as follows.

A coordinate frame $O^{\prime} X Y$ is established. The origin $O^{\prime}$ is located at one end of the screen surface which mounted on the fixed box beam and the $X$-direction is along the screen surface, as shown in Figure 4. $B$ is another end of the screen surface mounted on the floating box beam. $O^{\prime} B, O^{\prime} B^{\prime}$ represent the positions of the tensioned and slackened screen surface, respectively. $L$ is the maximum distance of $\left|O^{\prime} B\right|, l^{\prime}$ is the distance between the adjacent fixed screen beam and the floating screen beam $\left|O^{\prime} B^{\prime}\right|$. $l$ is the free length of the screen surface, respectively. $\Delta l$ is the tension length of the screen surface. $\lambda$ is the length of $\left|B B^{\prime}\right|$. Therefore, the equation of the screen surface can be given:

$$
\left\{\begin{array}{l}
L=l^{\prime}+\lambda, \\
\lambda=e(1+\cos \omega t), \\
\Delta l=L-l .
\end{array}\right.
$$

Based on three-tangent arcs theory, the following geometric relations can be obtained:

$$
\left\{\begin{array}{l}
l=2 \alpha(R+r), \\
l^{\prime}=2(R+r) \sin \alpha, \\
Y=-(R+r)(1-\cos \alpha),
\end{array}\right.
$$

where $R$ is the radius of the great arc in the middle; $r$ is the radius of the small arc at both ends. $O_{1}, O_{2}$, and $O_{3}$ are the centres of the three arcs. $\alpha$ is the angle between $O_{1} O_{2}, O_{1} O_{3}$ and the vertical direction. $Y$ is the deflection of the screen surface midpoint.

Substituting equation (18) into equation (17), the deflection of the surface midpoint $Y$ can be obtained. By taking the first and second derivatives of $Y$ to time $t$, the screen surface midpoint velocity and acceleration can be expressed as follows [30]:

$$
\left\{\begin{array}{l}
Y=-\frac{\sqrt{3}}{4} \sqrt{\Delta l^{2}-2 \Delta l L+2 e L(1+\cos \omega t)-e^{2}(1+\cos \omega t)^{2}}, \\
\dot{Y}=\frac{\sqrt{3}}{4} \frac{e \omega \sin \omega t(L-e(1+\cos \omega t))}{\sqrt{\Delta l^{2}-2 \Delta l L+2 e L(1+\cos \omega t)-e^{2}(1+\cos \omega t)^{2}}}, \\
\ddot{Y}=-\frac{\sqrt{3}}{4}\left(\frac{e \omega^{2} \cos \omega t(e-L)+e^{2} \omega^{2} \cos 2 \omega t}{\sqrt{\Delta l^{2}-2 \Delta l L+2 e L(1+\cos \omega t)-e^{2}(1+\cos \omega t)^{2}}}-\frac{(e \omega \sin \omega t(e+e \cos \omega t-L))^{2}}{\left(\Delta l^{2}-2 \Delta L+2 e L(1+\cos \omega t)-e^{2}(1+\cos \omega t)^{2}\right)^{3 / 2}},\right.
\end{array}\right.
$$

where $\dot{Y}, \ddot{Y}$ are the velocity and the acceleration of the screen surface midpoint along the ordinate, respectively.

\section{Experiment Set-Up}

Vibration characteristics of FFSCLS can be calculated based on the above kinematical model. To verify the accuracy and feasibility, an experiment was performed. The schematic diagram of the experimental platform is shown in Figure 5 while the site layout shown in Figure 6. During the experiment, an acceleration sensor was used to measure the vibration characteristics of the screen body and a laser displacement sensor was applied to measure the vibration characteristics of the screen surface. The
INV9832 ICP three-direction acceleration sensor was attached separately to the floating box and fixed screen box by the insulating medium magnet seat. Then, the acceleration of the screen body in three directions was measured, and the velocity and displacement can be obtained by numerical integration. The laser displacement sensor was fixed on a suspension bracket but keeping a distance from the screen surface. The deflection of the screen surface in $Y$-direction was tested and the velocity and acceleration can be obtained by numerical differentiation. The single acquisition system includes an INV3060s high-precision signal acquisition analyzer and a computer in which a real-time analysis software of Coinv DASP-V10 was installed. 


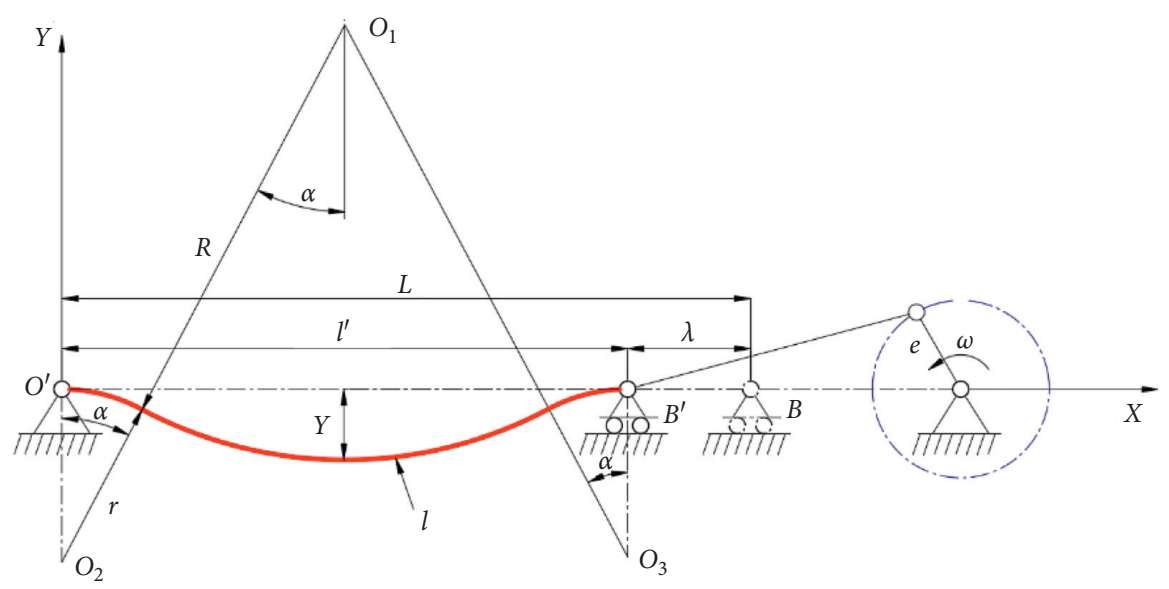

Figure 4: Kinematic model of the FFSCLS screen surface.

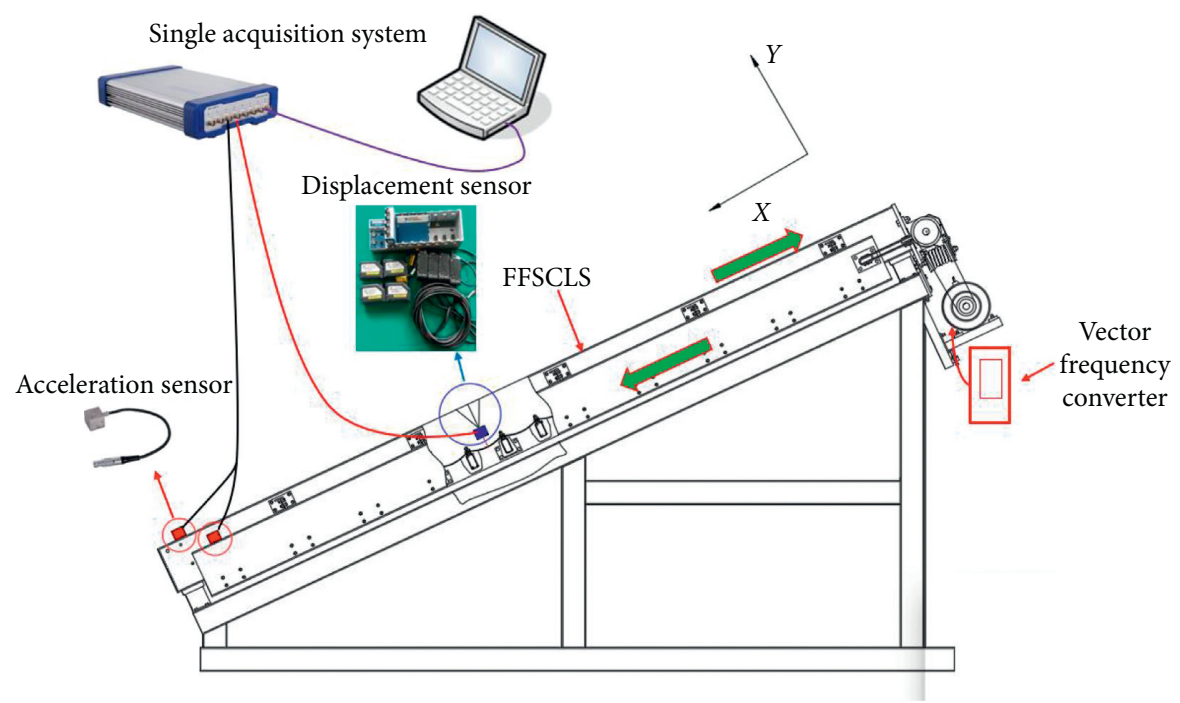

FIgURE 5: Schematic diagram of the experiment.

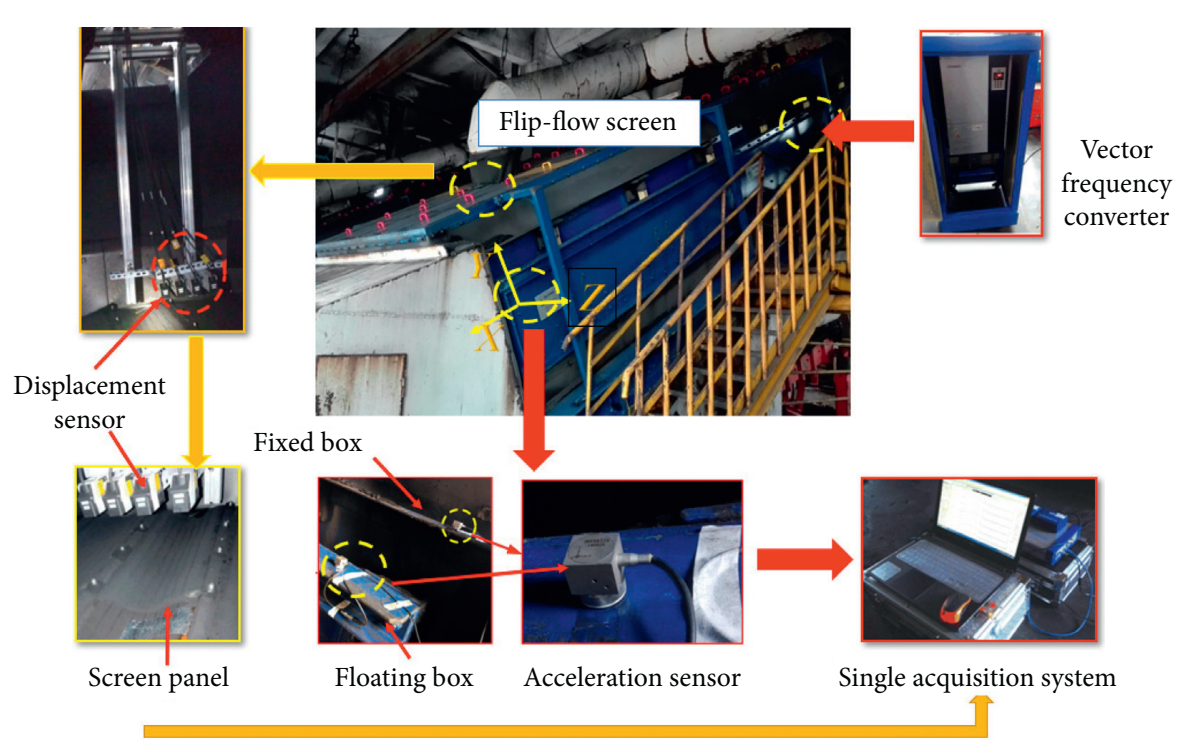

FIgURE 6: Site layout of the experiment. 
The drive motor rotational speed was $1480 \mathrm{rpm}(660 \mathrm{~V}$, $50 \mathrm{~Hz}$ ), and the transmission ratio $i=2.51$. Thus, the crankshaft rotational speed was $590 \mathrm{rpm}$. During the experiments, the crankshaft rotation speed range was around 500-615 rpm. Thus, the corresponding rotational speed range of the drive motor was $1243.2-1539.2 \mathrm{rpm}$ and the frequency converter regulating range was $42-52 \mathrm{~Hz}$.

\section{Results and Discussion}

4.1. Vibration Tests and Analyses. During the vibration experiment, all the data were sampled when the screening process was at a steady state. In the experimental system shown in Figures 5 and 6, the acceleration sensor and laser displacement sensor were connected to the signal acquisition analyzer through couples. Then, the signal acquisition analyzer was connected to the computer. The sampling frequency was set to $1000 \mathrm{~Hz}$, which was far from the maximum vibration frequency to ensure the received data fully include the real-time signals.

The velocities of the floating and fixed boxes obtained by kinematic model and experiment presented in Section 2.1 are shown in Figure 7. As shown in Figures 7(a) and 7(b), both the velocities in the $X$-direction of the screen body increase with the increase of $\omega$. Moreover, the experimental results are generally higher than that of theoretical ones, but consistency can be observed in general. Figure 7(a) shows that when rotational speed of the crackshaft $\omega$ increases from 51.8 to $64.2 \mathrm{rad}^{-1} \mathrm{~s}^{-1}$, the experimental results about velocity of the floating box increases from 432.0 to $541.4 \mathrm{~mm} \mathrm{~s}^{-1}$. The maximum relative error between the experimental results and theoretical results is approximately $6.96 \%$. Figure 7 (b) shows that the experimental results about velocity of the fixed box increase from 212.3 to $260.1 \mathrm{~mm} \mathrm{~s}^{-1}$. The maximum relative error between the experimental results and theoretical results is less than $4.71 \%$. Figure $7(\mathrm{c})$ shows that with the increase of $\omega$, the velocity in $Y$-direction also increases. With the maximum $\omega$ of $64.2 \mathrm{rad} \mathrm{s}^{-1}$ (converter frequency value is $52 \mathrm{~Hz}$ ) the velocity of floating and fixed screen box reaches $32.7 \mathrm{~mm} \mathrm{~s}^{-1}$ and $19.5 \mathrm{~mm} \mathrm{~s}^{-1}$, respectively. It can be found from Figure 7(d) that the velocity in the $Z$-direction of the floating and fixed screen boxes peaks at only $15.1 \mathrm{~mm} \mathrm{~s}^{-1}$ and $17.7 \mathrm{~mm} \mathrm{~s}^{-1}$, respectively, with $\omega$ of $59.2 \mathrm{rads}^{-1}$. Hence, compared to the velocity in the $X$-direction, the velocities in both $Y$ - and $Z$-directions can be neglected.

Figure 8 shows the accelerations in the $X$-direction of the screen body obtained by the experiments and the kinematic model. It can be found that theoretical results increase linearly with the increase of $\omega$ and an overall agreement between the experimental and theoretical results can be observed. As shown in Figure 8(a), with $\omega$ increase from 51.8 to $64.2 \mathrm{rads}^{-1}$, the experimental results of the accelerations in $X$-direction of the floating box increase from 22.5 to $34.6 \mathrm{~m} \mathrm{~s}^{-2}$ with some fluctuations. The accelerations of the fixed box presented in Figure 8(b) show a similar trend. The theoretical results increase linearly and the experimental values increase with fluctuations from 10.8 to $17.3 \mathrm{~m} \mathrm{~s}^{-2}$. Furthermore, relative error less than $6.0 \%$ between the experiments and calculations is observed. Hence, the reasonability of the kinematic model of the screen body at a steady state is proved.

During the operation of the FFSCLS, the rotational speed of the crankshaft $\omega$ also played an impartment role in the vibration of the screen surface. Therefore, it is necessary to investigate the effect of crackshaft rotational speed on the kinematic characteristics of the screen surface. The velocity $\dot{Y}$ and acceleration $\ddot{Y}$ of the midpoint of the screen surface were measured as a function of $\omega$, as shown in Figure 9. It is clear from Figure 9(a) that the velocity $\dot{Y}$ of the midpoint of screen surface increases with the increase of $\omega$. When $\omega$ increases from 51.8 to $64.2 \mathrm{rad} \mathrm{s}^{-1}$, the calculational values increase linearly from 864.2 to $1070.0 \mathrm{~mm} \mathrm{~s}^{-1}$, while the experimental results increase from 813.6 to $1120.0 \mathrm{~mm} \mathrm{~s}^{-1}$, but with some obvious fluctuations. Besides, the maximum error between the experiment and calculation is within $6.2 \%$. Figure 9(b) shows that the acceleration $\ddot{Y}$ of the midpoint of the screen surface also increases with the increase of $\omega$. When $\omega$ increases from 51.8 to $64.2 \mathrm{rad} \mathrm{s}^{-1}$, the experimental results increase from 78.6 to $121.3 \mathrm{~m} \mathrm{~s}^{-2}$ and the theoretical values increase from 76.9 to $117.8 \mathrm{~m} \mathrm{~s}^{-2}$, and the errors between the experiment and theory are only less than $5.6 \%$, indicating that the accuracy of the kinematic model of the screen surface proposed above is also well validated.

4.2. Vibration Characteristics of the Screen Body with Different Crackshaft Eccentricities. The parameters and the theoretical values of the FFSCLS used in this section are listed in Table 1. The masses of the floating box and the fixed box are $4515 \mathrm{~kg}$ and $9873 \mathrm{~kg}$, respectively. The rotational speed of the crankshaft is $59.2 \mathrm{rad} \mathrm{s}^{-1}$, which is equivalent to $566 \mathrm{rmin}^{-1}$. Through the kinematic model of the FFSCLS (equations (11) and (14)), it is clear that the vibration characteristics of the floating box and fixed box along the $X$-direction are proportional to the eccentricity $e$ of the crankshaft. The changes of the displacements, velocities, and accelerations of the floating box $\left(X_{1}, \dot{X}_{1}, \ddot{X}_{1}\right)$ and fixed box $\left(X_{2}, \dot{X}_{2}, \ddot{X}_{2}\right)$ with the eccentricity $e$ of 6,8 , and $12 \mathrm{~mm}$ are shown in Figure 10. It can be found that all the vibration characteristics of the screening body fluctuate harmonically during the working process about the FFSCLS. Furthermore, both the maximum values of $\left|X_{1}\right|,\left|X_{2}\right|$ (Figures 10(a) and 10(b)), $\left|\dot{X}_{1}\right|,\left|\dot{X}_{2}\right|$ (Figures 10(c) and 10(d)), and $\left|\ddot{X}_{1}\right|,\left|\ddot{X}_{2}\right|$ (Figures 10(e) and 10(f)) increase with the increase of $e$.

Figure 10(a) shows that the displacement $X_{1}$ presents a cosine variation law during the working process of the FFSCLS. When the eccentricity $e$ is of $6 \mathrm{~mm}$, the displacement $X_{1}$ gradually decreases from $4.0 \mathrm{~mm}$ to $-4.0 \mathrm{~mm}$ (negative sign indicates an opposite direction of displacement) in the first half of the vibration period ( 0 to $0.05 \mathrm{~s}$ ) and increases from $-4.0 \mathrm{~mm}$ to $4.0 \mathrm{~mm}$ in the second half of the vibration period ( 0.05 to $0.1 \mathrm{~s}$ ). The displacement amplitude of the floating box $\left|X_{1}\right|$ increases from $4.0 \mathrm{~mm}$ to $5.4 \mathrm{~mm}$ when the eccentricity $e$ increases from $6 \mathrm{~mm}$ to $8 \mathrm{~mm}$. Then, when $e$ further increases to $12 \mathrm{~mm}$, a larger increase in the displacement amplitude of $\left|X_{1}\right|$ is observed, whose value is $8.0 \mathrm{~mm}$. Figure 10(b) shows the displacement of the fixed 


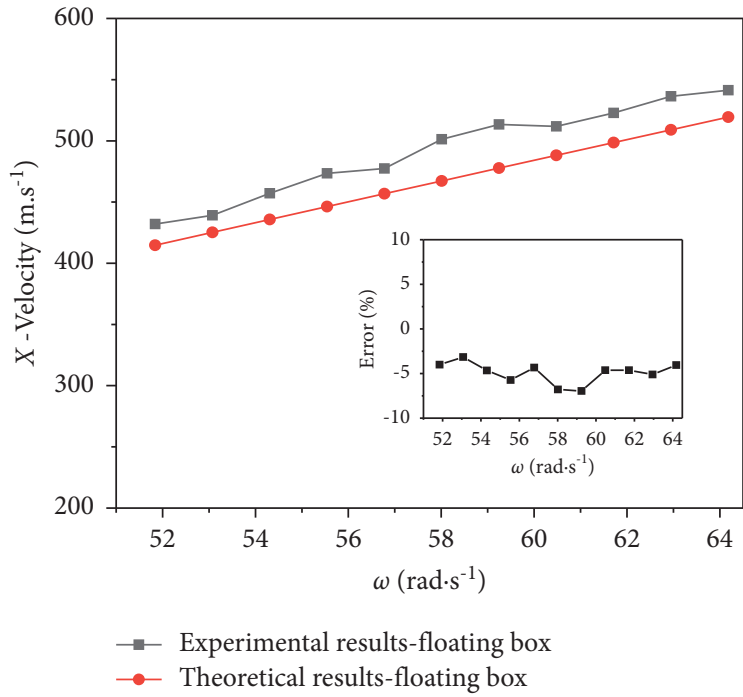

(a)

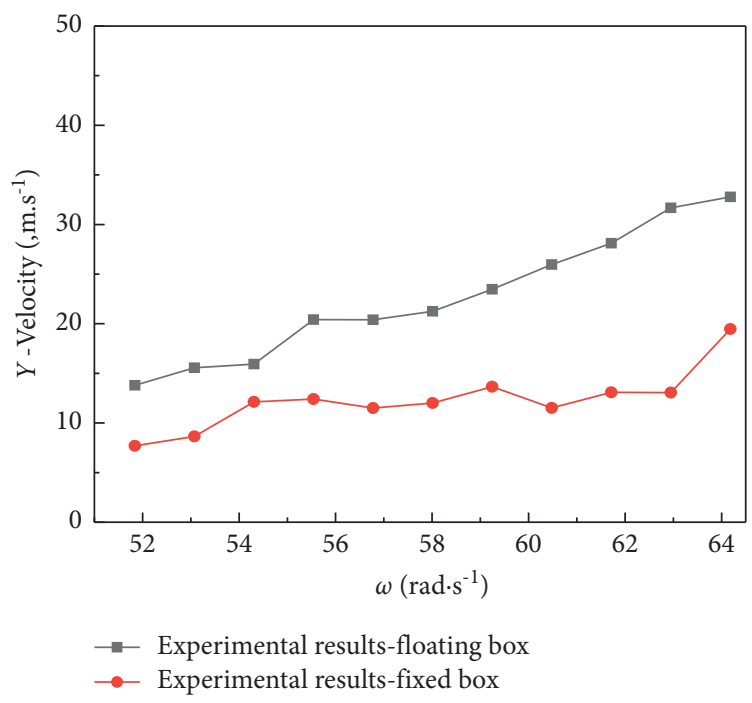

(c)

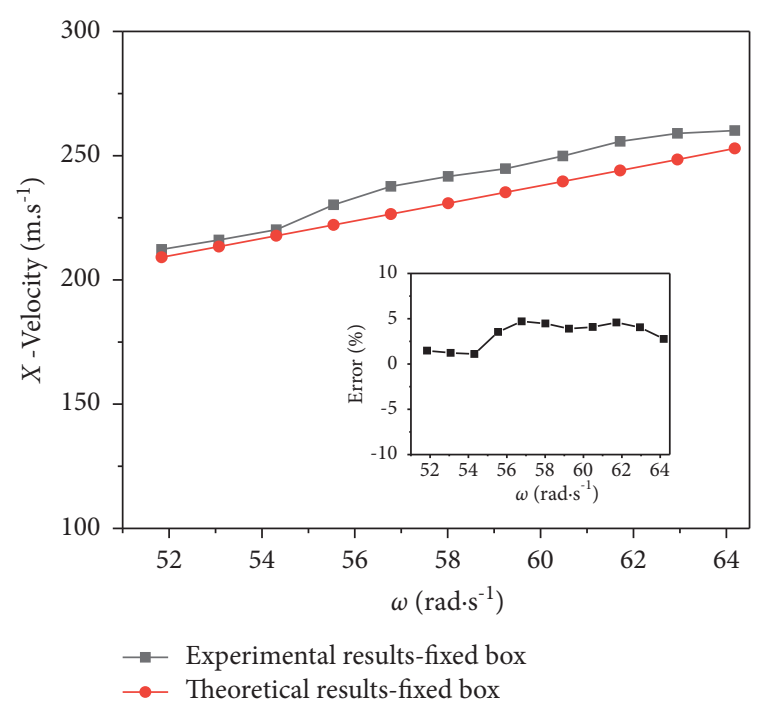

(b)

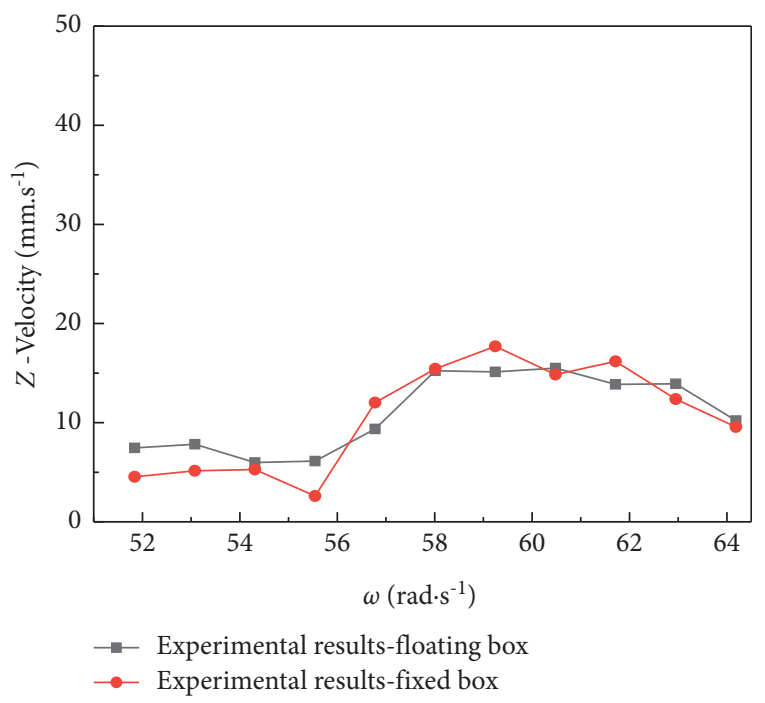

(d)

FIgUre 7: Comparisons of the velocities of the screen body between experiments and calculations (a) for floating box along $X$-direction, (b) for fixed box along $X$-direction, and floating box and fixed box along (c) $Y$-direction and (d) Z-direction.

box $X_{2}$. Based on the working principle of the FFSCLS, the motion directions of the floating box and the fixed box are always opposite, which means that the phase difference of the displacement curves between the floating box and the fixed box is $180^{\circ}$. Hence, the corresponding displacement $X_{2}$ presents a sine variation law during the working process of the FFSCLS. The amplitude of the displacement of the fixed box $\left|X_{2}\right|$ increases from $2.0 \mathrm{~mm}$ to $2.6 \mathrm{~mm}$ when $e$ increases from $6 \mathrm{~mm}$ to $8 \mathrm{~mm}$. Similarly, when $e$ further increases to $12 \mathrm{~mm}$, the increase of $\left|X_{2}\right|$ is doubled, whose value is about $4.0 \mathrm{~mm}$. It should be noticed that due to the greater mass, the amplitude of the fixed screen box is always smaller than that of the corresponding floating screen box.

Figures 10(c) and 10(d) show the velocities data of the screen body, which can be obtained by first derivative of the displacement data shown in Figures 10(a) and 10(b). Both velocities of the floating box and the fixed box fluctuate harmonically during the working process of the FFSCLS. When the eccentricity $e$ increases from $6 \mathrm{~mm}$ to $8 \mathrm{~mm}$, the amplitude of the velocity of the floating box $\left|\dot{X}_{1}\right|$ increases from $238.1 \mathrm{~mm} \mathrm{~s}^{-1}$ to $317.5 \mathrm{~mm} \mathrm{~s}^{-1}$ and then increases rapidly to $476.3 \mathrm{~mm} \mathrm{~s}^{-1}$ when $e$ further increases to $12 \mathrm{~mm}$. Similarly, the amplitude of the velocity of the fixed box $\left|\dot{X}_{2}\right|$ increases from $117.2 \mathrm{mms}^{-1}$ to $234.5 \mathrm{mms}^{-1}$ when $e$ increases from $6 \mathrm{~mm}$ to $12 \mathrm{~mm}$, whose values are smaller than that of the floating box. Figures $10(\mathrm{e})$ and 10(f) show the accelerations of the screen body, which are drawn based on the second derivative of the displacement data. When the eccentricity $e$ increases from $6 \mathrm{~mm}$ to $12 \mathrm{~mm}$, the amplitudes of the acceleration of the floating box $\left|\ddot{\mathrm{X}}_{1}\right|$ and the fixed box $\left|\ddot{X}_{2}\right|$ will increase from $14.2 \mathrm{~m} \mathrm{~s}^{-2}$ to $28.3 \mathrm{~m} \mathrm{~s}^{-2}$ and from $7.0 \mathrm{~m} \mathrm{~s}^{-2}$ to $14.0 \mathrm{~m} \mathrm{~s}^{-2}$, respectively. It should be noticed that both a relatively low velocity (acceleration) and a relatively high velocity (acceleration) are detrimental to the screening 


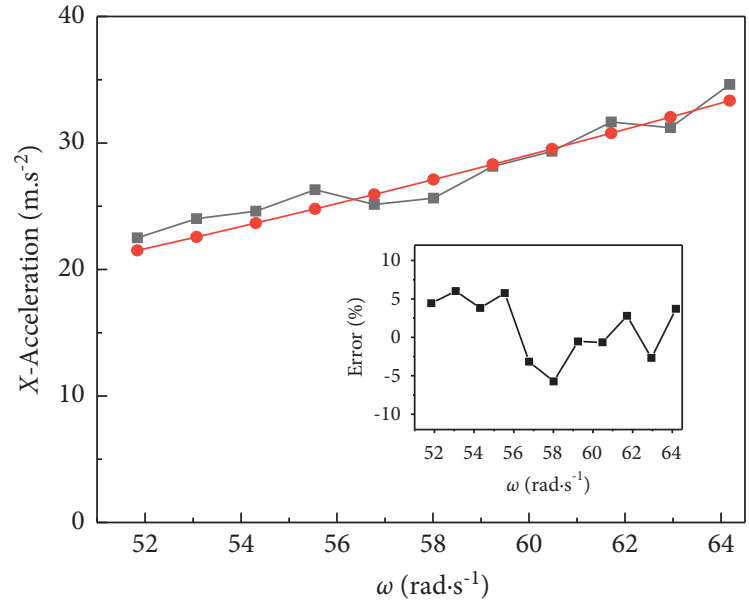

Experimental results-floating box

- Theoretical results-floating box

(a)

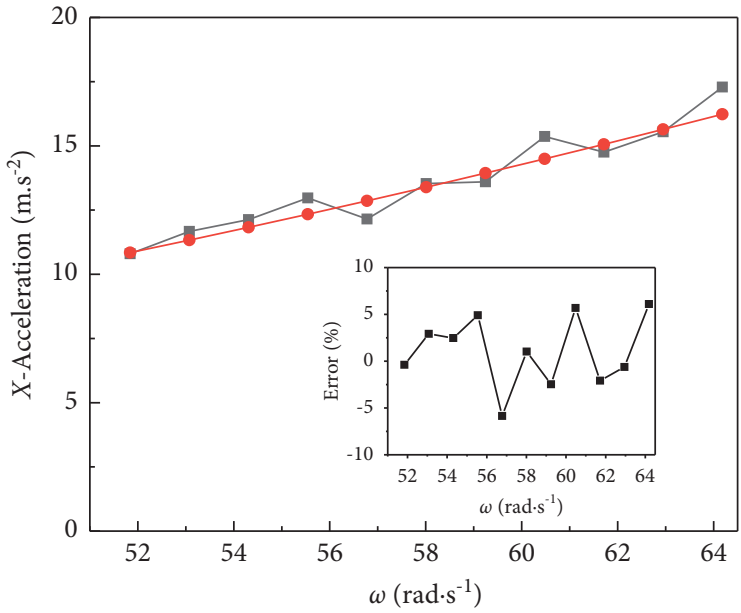

$\rightarrow$ Experimental results-fixed box

$\rightarrow$ Theoretical results-fixed box

(b)

FIGURE 8: Comparisons of accelerations of the screen body between experiments and calculations (a) for floating box along $X$-direction and (b) for fixed box along $X$-direction.

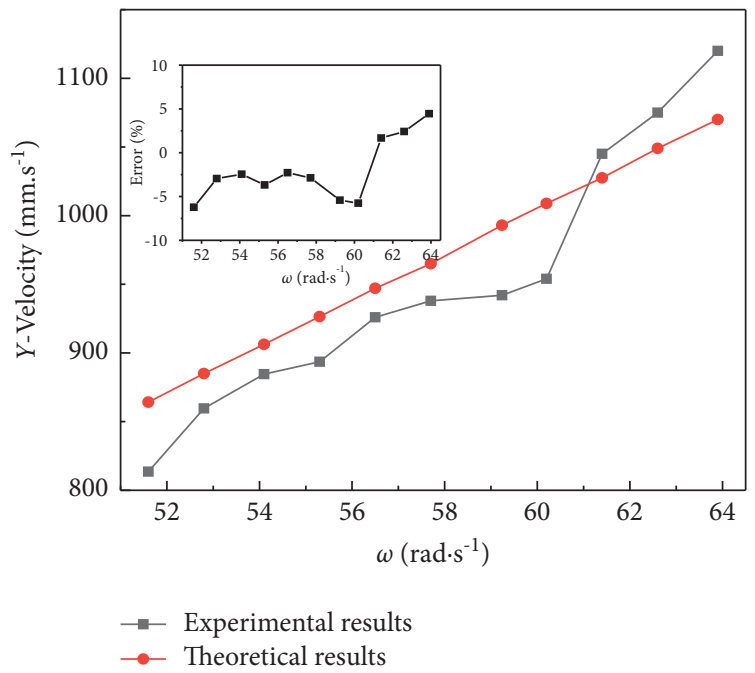

(a)

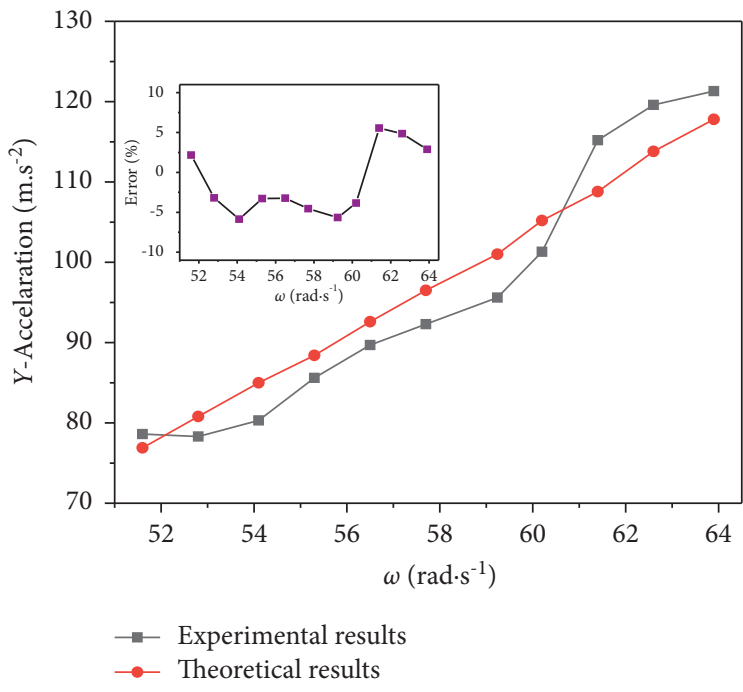

(b)

FIGURE 9: Comparisons of (a) velocity and (b) acceleration of the midpoint of screen surface along Y-direction between the experiments and calculations.

TABle 1: Parameters used in Section 4.2

\begin{tabular}{|c|c|c|}
\hline Item & & Value \\
\hline Mass of the floating box, $m_{1}(\mathrm{~kg})$ & & 4515 \\
\hline Mass of the fixed box, $m_{2}(\mathrm{~kg})$ & & 9873 \\
\hline The rotational speed of the crankshaft, $\omega\left(\mathrm{rad}^{-1}\right)$ & & 59.2 \\
\hline The eccentricity of the crankshaft, $e(\mathrm{~mm})$ & 6 & $8 \quad 12$ \\
\hline
\end{tabular}

process of the flip-flow screen. A low velocity might cause the accumulation of particles on the screen surface, while a high velocity would reduce the residence time of particles on the screen deck, both of which could reduce the screening efficiency. Therefore, a reasonable choice of the eccentricity $e$ is necessary and the value should be between 6 and $12 \mathrm{~mm}$.

\subsection{Vibration Characteristics of the Screen Body with Different} Crackshaft Rotational Speeds. Table 2 lists the parameters applied in this section. The eccentricity of the crankshaft $e$ used here is $8 \mathrm{~mm}$. The stiffness coefficient of the springs $k_{2 X}$ is $2.47 \times 10^{6} \mathrm{Nm}^{-1}$ and the mass of the screen body remains unchanged. Based on equations (11) and (14), the vibration characteristics of the screen body are directly affected by the rotational speed $\omega$. The vibration amplitudes of the screen body with different $\omega$ are shown in Figure 11. Before the 

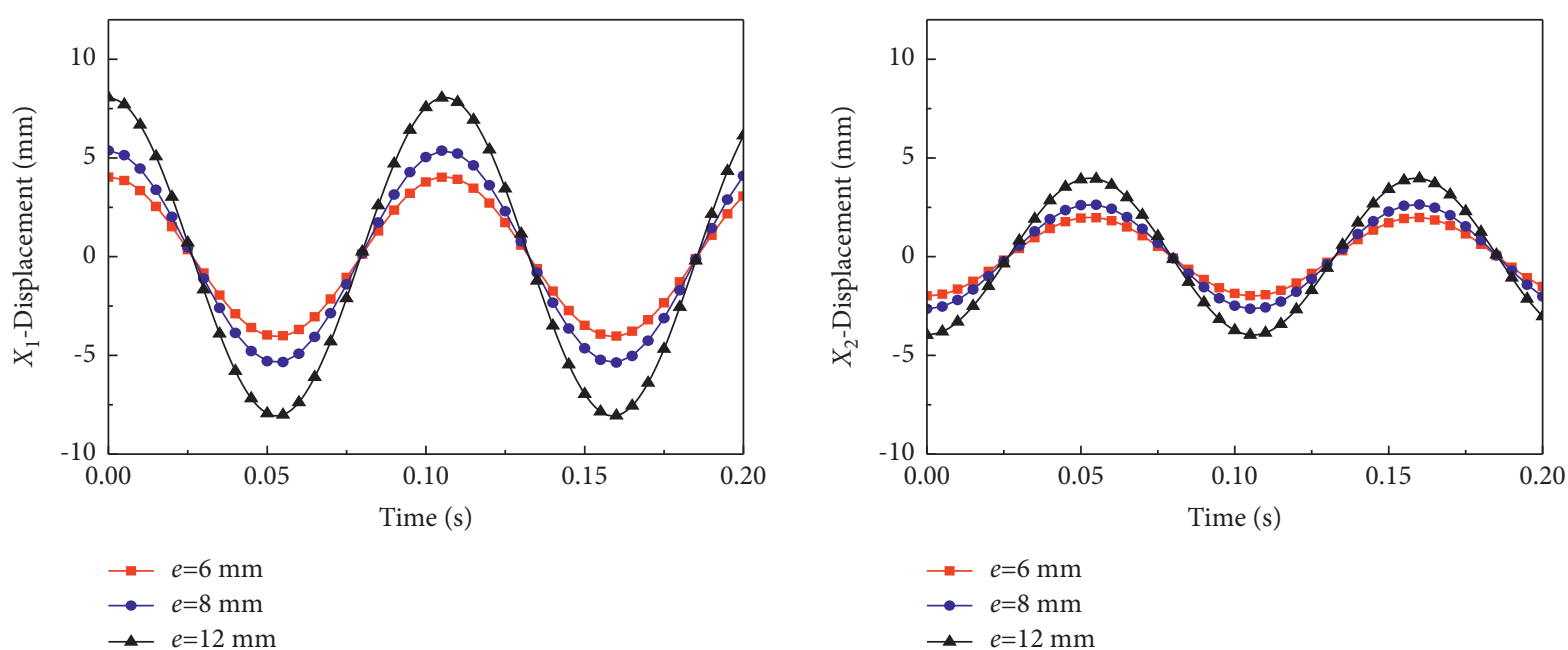

(a)
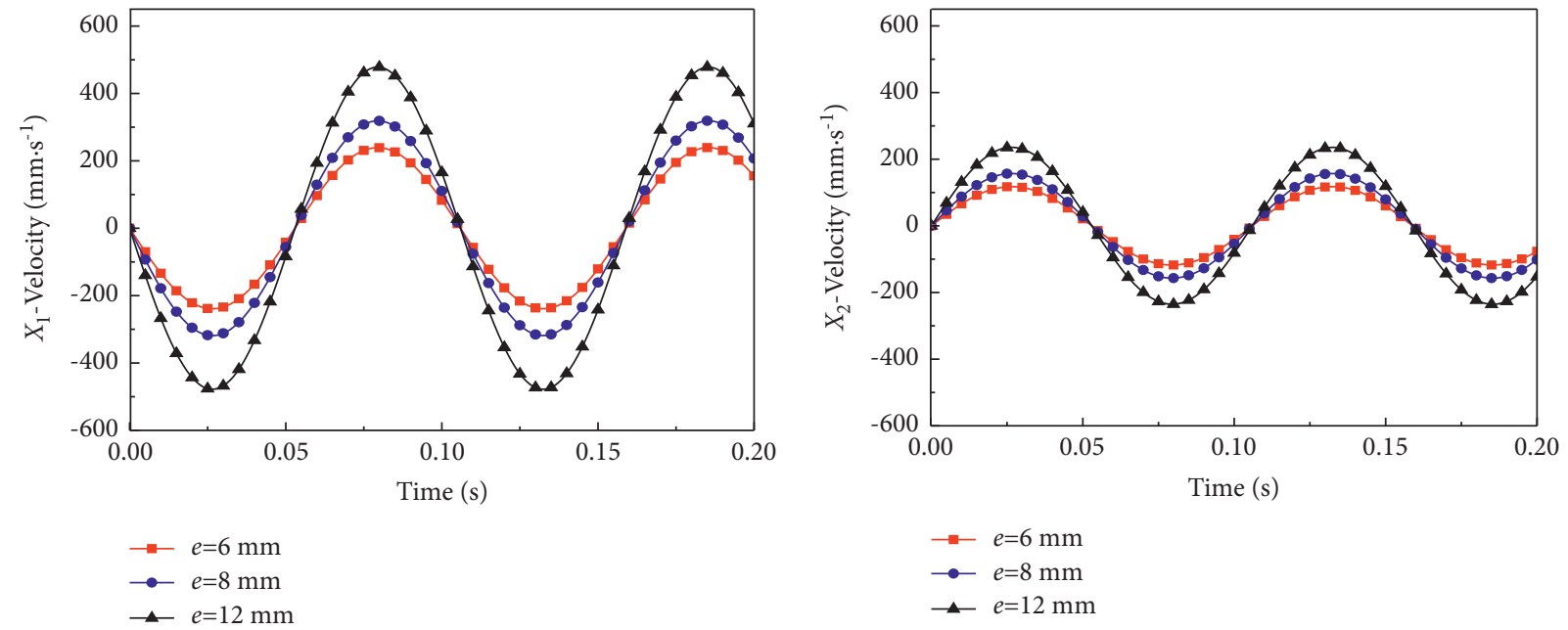

(c)

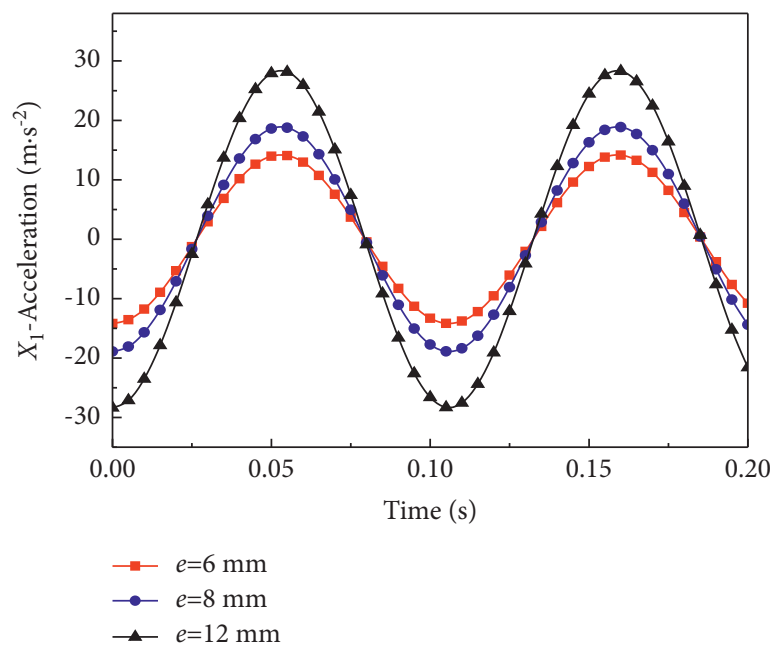

(e)

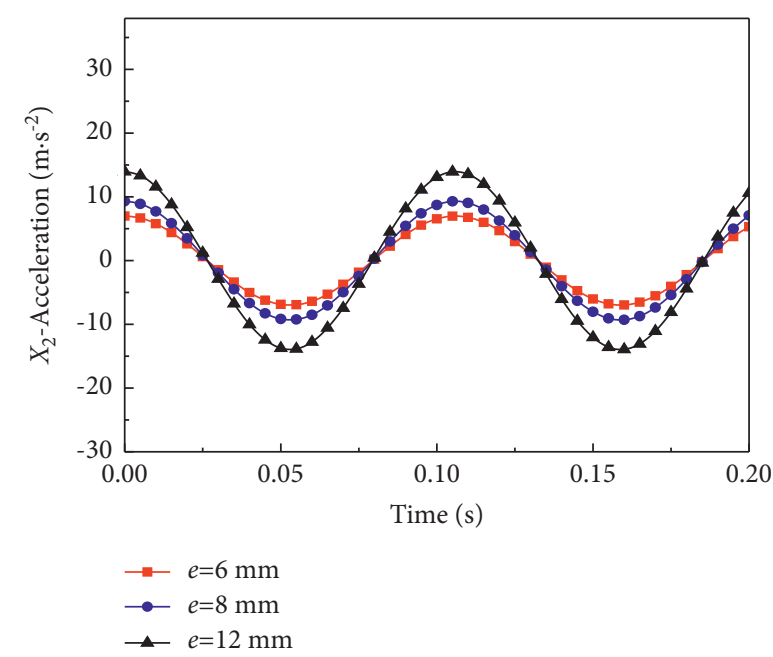

(f)

FIGURE 10: Vibration characteristics of the screen body with different $e$ : (a, b) displacement $\mathrm{X}_{1}, \mathrm{X}_{2} ;(\mathrm{c}, \mathrm{d})$ velocity $\dot{X}_{1},\left|\dot{X}_{2}\right| ;(\mathrm{e}, \mathrm{f})$ acceleration $\ddot{X}_{1}, \ddot{X}_{2}$. 
Table 2: Parameters used in Section 4.3.

\begin{tabular}{lll}
\hline Item & Value & \\
\hline The eccentricity of the crankshaft, $e(\mathrm{~mm})$ & 8 & \\
Stiffness coefficients of the springs, $k_{2 X}\left(\mathrm{Nm}^{-1}\right)$ & $2.47 \times 10^{6}$ & 59.2 \\
Rotational speed of the crankshaft, $\omega\left(\mathrm{rad} \mathrm{s}^{-1}\right)$ & 51.8 & 64.2 \\
\hline
\end{tabular}

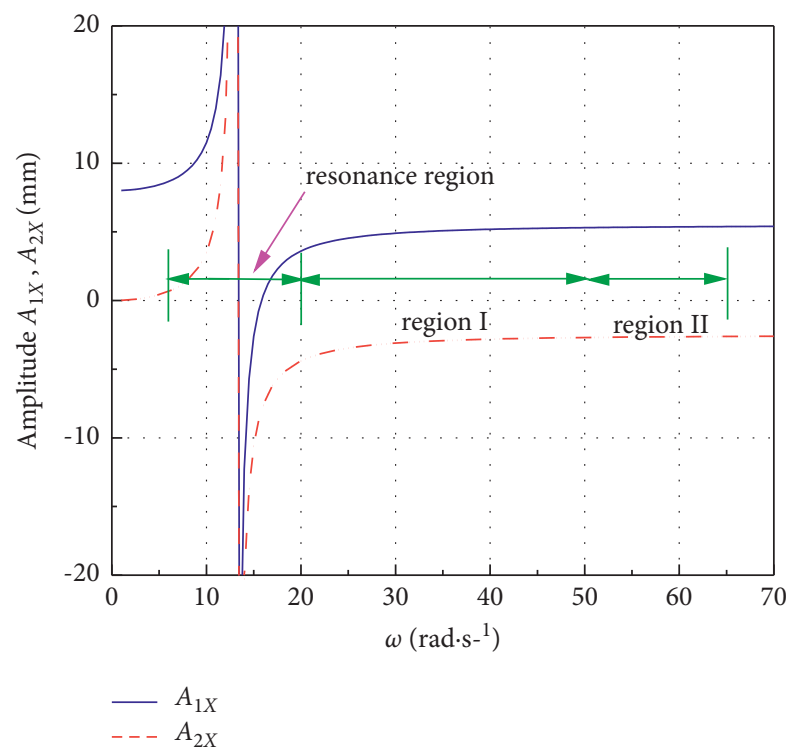

FIgURE 11: Vibration amplitude of the screen body with different $\omega$.

resonance angular frequency $\omega_{\mathrm{n} X}\left(13.1 \mathrm{rads}^{-1}\right)$, both the amplitudes of the floating box and the fixed box are positive and increase exponentially with the increase of the crackshaft rotational speed $\omega$. When $\omega$ exceeds $\omega_{\mathrm{nX}}$, the vibration amplitudes of the screen body become negative, and the amplitude of the floating box $A_{1 X}$ decreases exponentially to 0 when $\omega$ is about $15.8 \mathrm{rads}^{-1}$ and then gradually increases with $\omega$ and remains stable at around $5.35 \mathrm{~mm}$ eventually. The amplitude of the fixed box $A_{2 X}$ decreases exponentially when $\omega$ is smaller than $20 \mathrm{rad}^{-1}$. Then, the amplitude of the fixed box decreases slightly and remains stable at about $-2.6 \mathrm{~mm}$. It should be noticed that excessive vibration amplitudes of the screen body could be obtained when $\omega$ is within the resonance region, which would induce unstable working conditions of the flip-flow screen. When $\omega$ is between about $20 \mathrm{rads}^{-1}$ and $50 \mathrm{rad}^{-1}$ (region I), the vibration motion directions of the floating box and the fixed box are opposite, the screen body could move correctly. However, the rotational speed $\omega$ is relatively slow leading to a low velocity and acceleration about the screen body, which would induce a lower screening performance. When $\omega$ is within region II, both the vibration amplitudes of the floating box and the fixed box are stable and a relatively high screening performance could be obtained in practice. A further increase of $\omega$ (after region II) would hardly increase the vibration amplitudes, but the amplitudes of velocity and acceleration about the screen body will increase rapidly. High velocity and acceleration amplitudes may reduce the screening efficiency of the FFSCLS. Moreover, when the rotational speed is too high, both the alternating loads applied on the springs and the machine noise will increase, and the machine service life will be reduced. Thus, the vibration characteristics of the screen body should be controlled.

The effects of the rotational speed $\omega$ on the kinematic characteristics of the screen body are shown in Figure 12. The amplitudes of the displacement of the floating box $\left|X_{1}\right|$ (Figure 12(a)) and the fixed box $\left|X_{2}\right|$ (Figure 12(b)) change slightly with the increase of $\omega$. When the values of rotational speed $\omega$ are 51.8, 59.2, and $64.2 \mathrm{rads}^{-1}$, the maximum amplitudes of the displacement of the floating box $\left|X_{1}\right|$ are $5.33,5.37$ and $5.40 \mathrm{~mm}$, respectively, while those of the fixed box $\left|X_{2}\right|$ are $2.69,2.65$, and $2.63 \mathrm{~mm}$, respectively. The changes in displacement amplitude are relatively small.

The maximum amplitude of the velocity of the floating box $\left|\dot{X}_{1}\right|$ (Figure 12(c)), the fixed box $\left|\dot{X}_{2}\right|$ (Figure 12(d)) and the maximum amplitude of the acceleration of the floating box $\left|\ddot{X}_{1}\right|$ (Figure 12(e)), and the fixed box $\left|\ddot{X}_{2}\right|$ (Figure 12(f)) increase relatively significantly with the increase of $\omega$. When the rotational speed $\omega$ increases from $51.8 \mathrm{rads}^{-1}$ to $64.2 \mathrm{rads}^{-1}$, the maximum amplitudes of the velocity $\left|\dot{X}_{1}\right|$ and the acceleration $\left|\ddot{X}_{1}\right|$ will increase from $276.2 \mathrm{~mm} \mathrm{~s}^{-1}$ to $346.2 \mathrm{~mm} \mathrm{~s}^{-1}$ and from $14.3 \mathrm{~m} \mathrm{~s}^{-2}$ to $22.2 \mathrm{~m} \mathrm{~s}^{-2}$, respectively. The maximum amplitudes of the velocity $\left|\dot{X}_{2}\right|$ and the maximum acceleration $\left|\ddot{X}_{2}\right|$ will increase from $139.3 \mathrm{~mm}^{-1}$ to $168.5 \mathrm{~mm} \mathrm{~s}^{-1}$ and from $7.2 \mathrm{~m} \mathrm{~s}^{-2}$ to $10.8 \mathrm{~m} \mathrm{~s}^{-2}$, respectively. It should be noticed that when $\omega$ increases from $51.8 \mathrm{rad} \mathrm{s}^{-1}$ to $64.2 \mathrm{rad} \mathrm{s}^{-1}$, the displacement amplitude of $\left|X_{1}\right|$ only increases by $1.3 \%$, but the velocity amplitude of $\left|\dot{X}_{1}\right|$ and the 


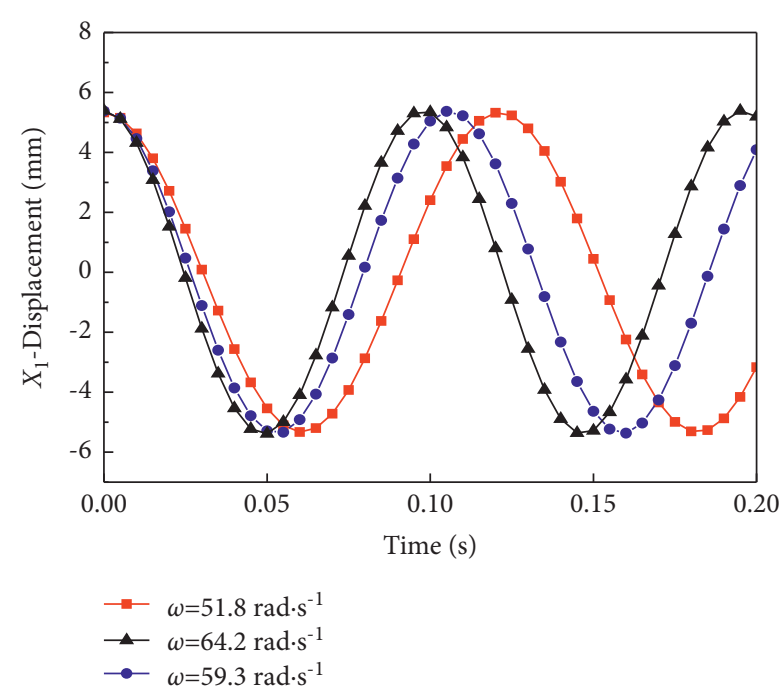

(a)

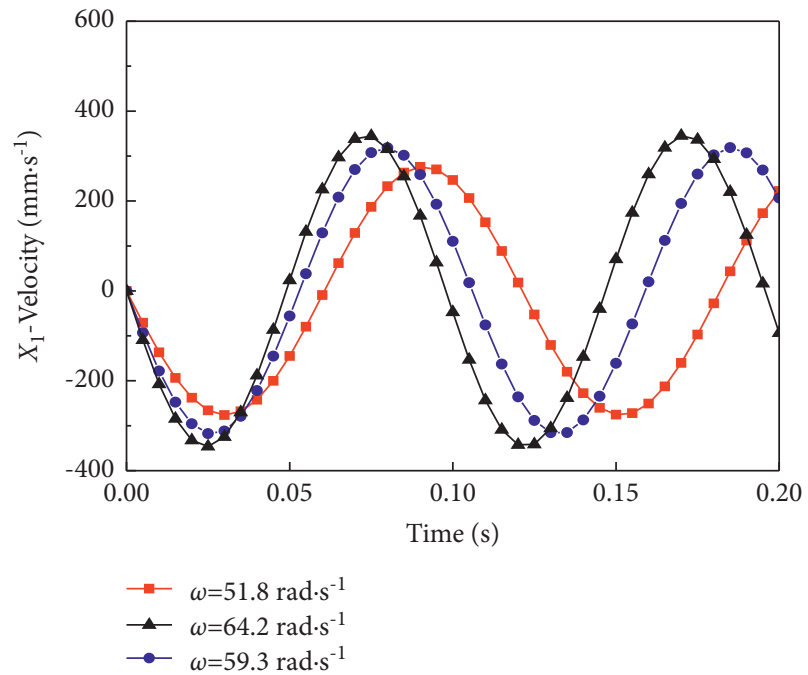

(c)

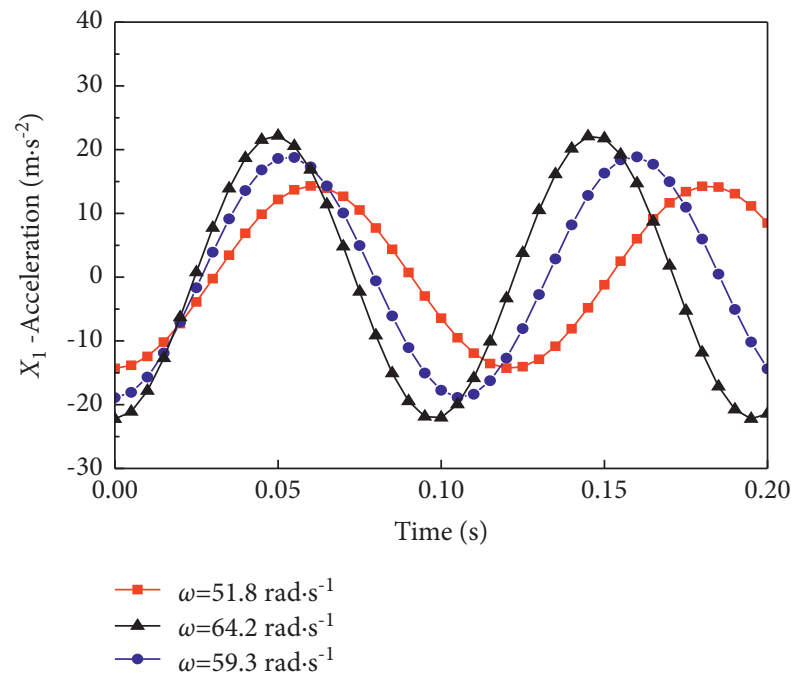

(e)

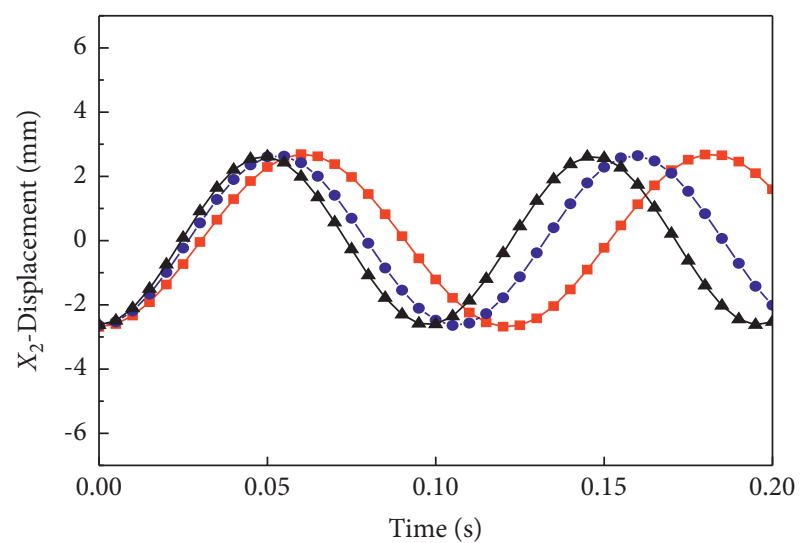

$\longrightarrow \omega=51.8 \mathrm{rad} \cdot \mathrm{s}^{-1}$
$\longrightarrow \omega=64.2 \mathrm{rad} \cdot \mathrm{s}^{-1}$
$\rightarrow \omega=59.3 \mathrm{rad} \cdot \mathrm{s}^{-1}$

(b)

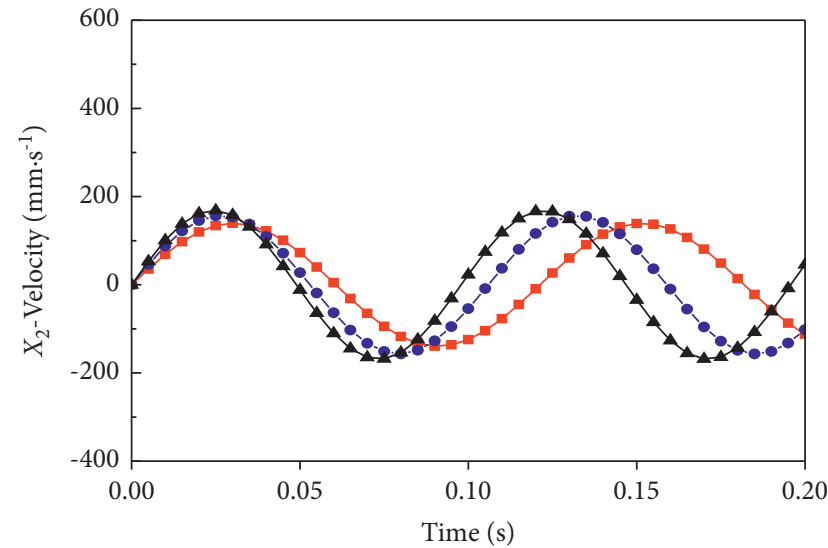

$\rightarrow \omega=51.8 \mathrm{rad} \cdot \mathrm{s}^{-1}$

$\neg \omega=64.2 \mathrm{rad} \cdot \mathrm{s}^{-1}$

$\rightarrow \omega=59.3 \mathrm{rad} \cdot \mathrm{s}^{-1}$

(d)

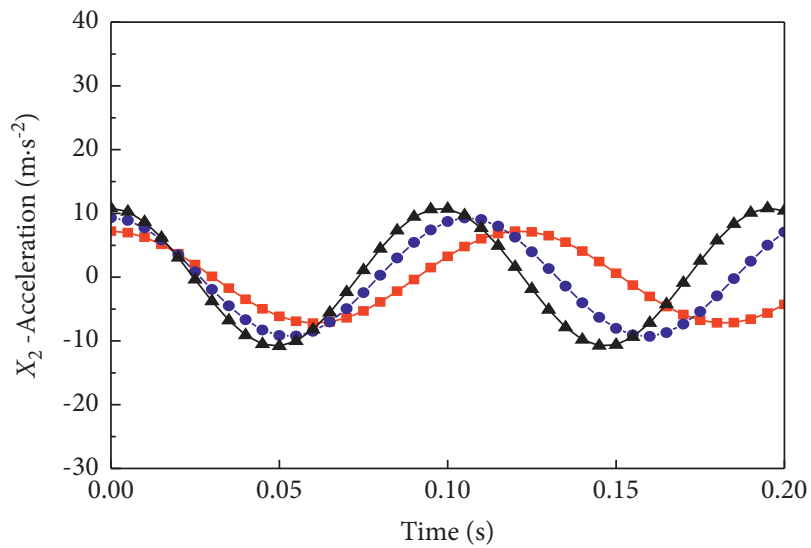

$\longrightarrow \omega=51.8 \mathrm{rad} \cdot \mathrm{s}^{-1}$
$\multimap \omega=64.2 \mathrm{rad} \cdot \mathrm{s}^{-1}$
$\rightarrow \omega=59.3 \mathrm{rad} \cdot \mathrm{s}^{-1}$

(f)

FIGURE 12: Vibration characteristics of the screen body with different $\omega$. (a, b) Displacement $X_{1}, X_{2}$; (c, d) velocity $\dot{X}_{1}, \dot{X}_{2} ;($ e, f) acceleration $\ddot{X}_{1}, \ddot{X}_{2}$. 
TABle 3: Parameters used in Section 4.4.

\begin{tabular}{|c|c|c|c|}
\hline Item & & Value & \\
\hline The maximum distance between the two ends, $L(\mathrm{~mm})$ & & 315 & \\
\hline The rotational speed of the crankshaft, $\omega\left(\mathrm{rad}^{-1}\right)$ & & 59.2 & \\
\hline The eccentricity of the crankshaft, $e(\mathrm{~mm})$ & & 8 & \\
\hline Tension length, $\Delta l(\mathrm{~mm})$ & -5 & -10 & -15 \\
\hline
\end{tabular}

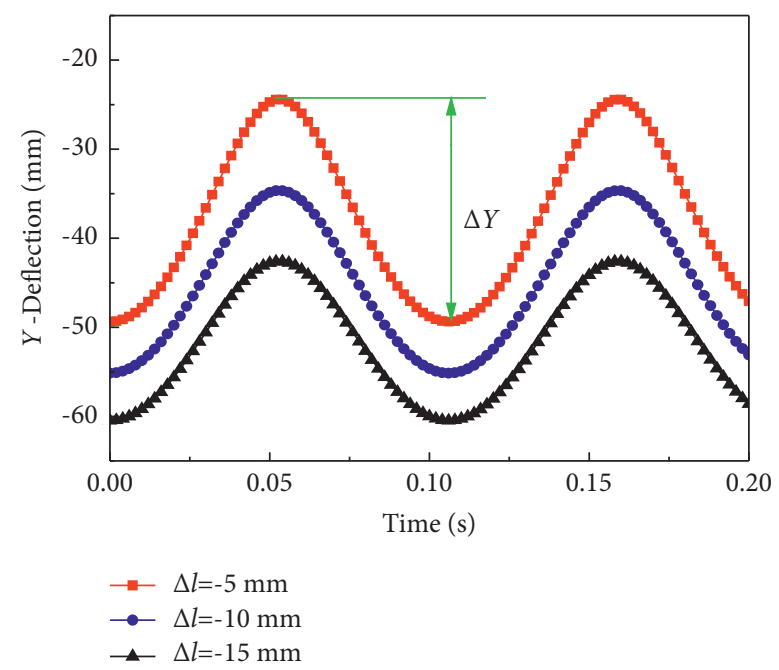

(a)

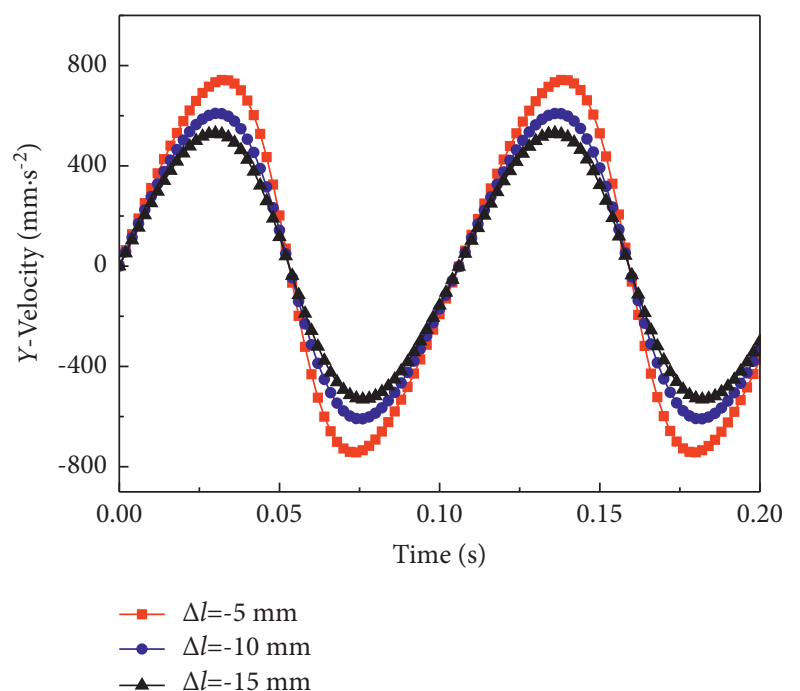

(b)

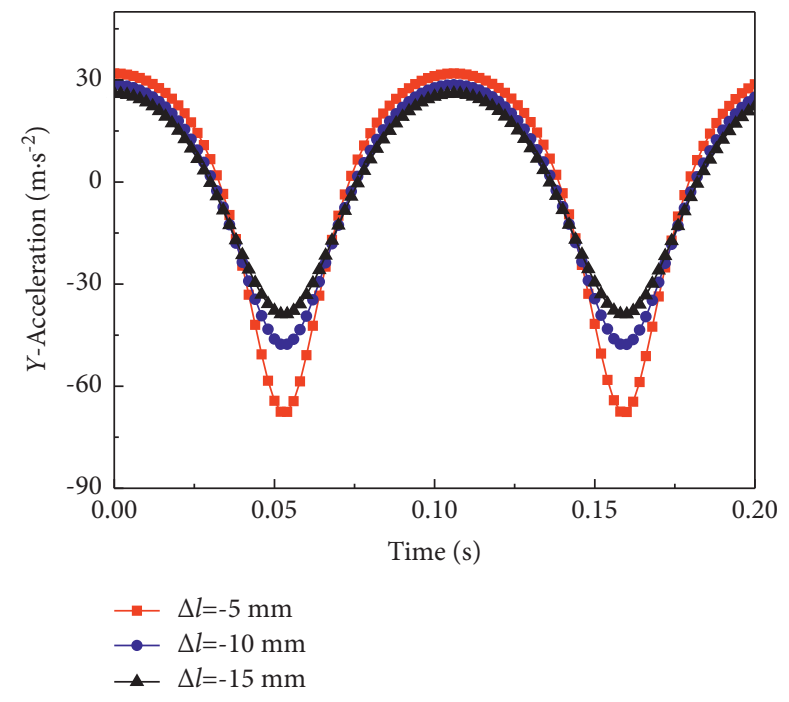

(c)

FIGURE 13: Vibration characteristics of the screen surface midpoint with different tension lengths $\Delta l$. (a) Deflection $Y$, (b) velocity $\dot{Y}$, and (c) acceleration $\ddot{Y}$.

acceleration amplitude of $\left|\ddot{X}_{1}\right|$ increase by $20.2 \%$ and $35.6 \%$, respectively. The displacement amplitude of $\left|X_{2}\right|$ decreases by only $2.3 \%$, but the velocity amplitude of $\left|\dot{X}_{2}\right|$ and the acceleration amplitude of $\left|\ddot{X}_{2}\right|$ increase by $17.3 \%$ and $33.3 \%$, respectively. So, when the crackshaft rotational speeds $\omega$ are beyond a certain range, further increase of $\omega$ will cause the vibration characteristics of the screen body increase rapidly, which is harmful to the screening machine. Moreover, the increase of $\omega$ also increases the vibration frequency of the screen surface. Therefore, a preferred crackshaft rotational speed $\omega$ is especially necessary while the value should be within 51.8 to $64.2 \mathrm{rad}^{-1}$.

4.4. Vibration Characteristics of the Screen Surface with Different Tension Lengths. Based on equation (19), the vibration characteristics of the screen surface along the $Y$ direction are proportional to the tension length $\Delta l$ when the 


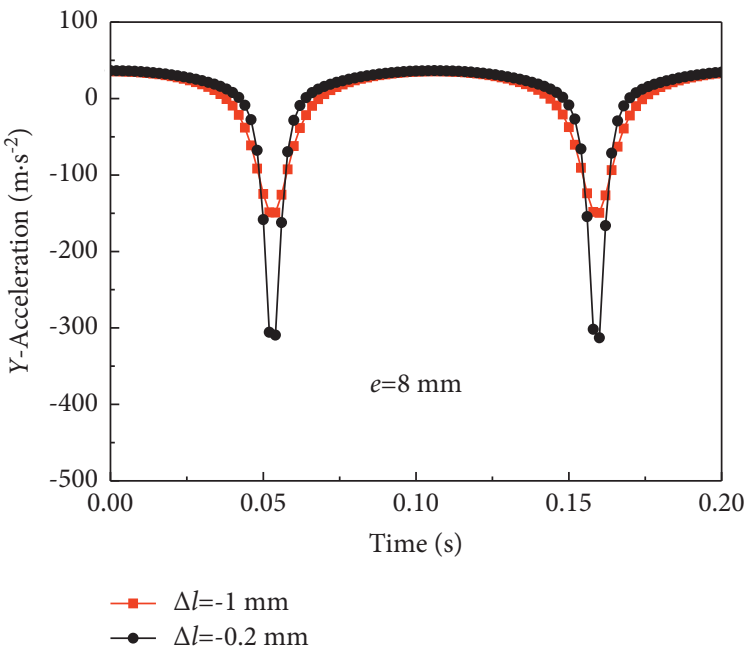

(a)

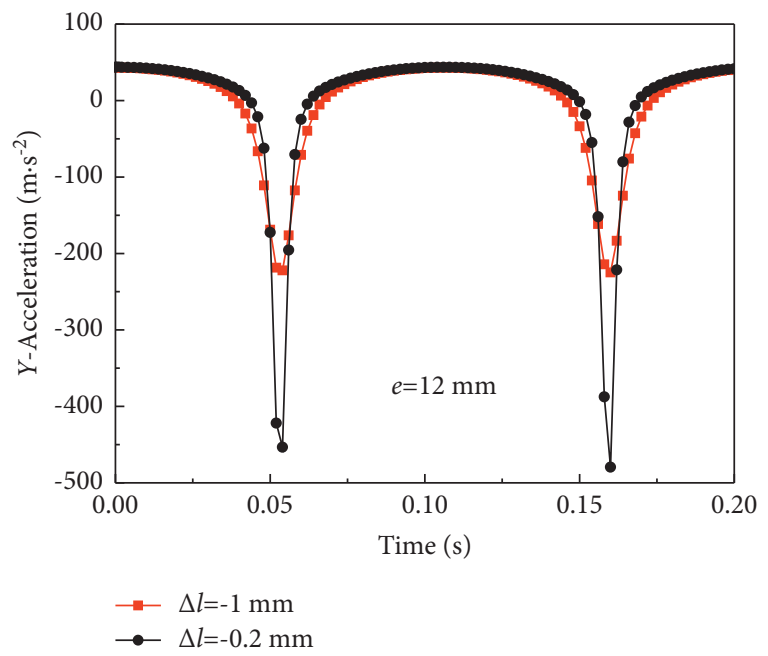

(b)

FIgURE 14: Acceleration of the screen surface under extreme conditions. (a) $e=8 \mathrm{~mm}$; (b) $e=12 \mathrm{~mm}$.

rest of the parameters are given. The parameters used in this section are listed in Table 3. The maximum distance between the two ends of the surface $L$ is $315 \mathrm{~mm}$, the rotational speed of the crankshaft $\omega$ is $59.2 \mathrm{rad}^{-1}$, and the eccentricity of the crankshaft $e$ is $8 \mathrm{~mm}$, respectively.

The deflection $Y$, the velocity $\dot{Y}$, and the acceleration $\ddot{Y}$ of the surface midpoint along the $Y$-direction with a different value of tension length $\Delta l$ are shown in Figure 13 . Figure 13(a) shows that the deflection $Y$ presents a regular variation law during the vibration of the screen surface. When $\Delta l$ is $-5 \mathrm{~mm}$, the deflection $Y$ gradually increases from $-49.3 \mathrm{~mm}$ to $-24.4 \mathrm{~mm}$ (negative values indicate the maximum distance $L$ is shorter than free length $l$ ) in the first half of the vibration period ( 0 to $0.05 \mathrm{~s}$ ) and decreases from $-24.4 \mathrm{~mm}$ to $-49.3 \mathrm{~mm}$ in the second half of the vibration period $(0.05$ to $0.1 \mathrm{~s})$. The valleys and peaks of the wave indicate the screen surface is in the states of relaxation and relative tension. The amplitude of $\Delta Y$ (i.e., the difference between the maximum $Y$ at the peak of the wave and the minimum $Y$ at the valley of the wave) decreases from $24.9 \mathrm{~mm}$ to $20.5 \mathrm{~mm}$ when $\Delta l$ decreases from $-5 \mathrm{~mm}$ to $-10 \mathrm{~mm}$. Then, when $\Delta l$ further decreases to $-15 \mathrm{~mm}, \Delta Y$ even reduces to $17.8 \mathrm{~mm}$. With the decrease of the tension length $\Delta l$, the curves of deflection $Y$ are similar, but the deflection amplitude $\Delta Y$ will be reduced.

As shown in Figure 13(b), the velocity amplitude $|\dot{Y}|$ also decreases with the decrease of $\Delta l$. The corresponding velocity amplitudes $|\dot{Y}|$ with $\Delta l$ of $-5 \mathrm{~mm},-10 \mathrm{~mm}$, and $-15 \mathrm{~mm}$ are $742.3 \mathrm{~mm} \mathrm{~s}^{-1}, 608.1 \mathrm{~mm} \mathrm{~s}^{-1}$, and $526.4 \mathrm{~mm} \mathrm{~s}^{-1}$, respectively. Compared to $\dot{Y}$ with $\Delta l$ of $-15 \mathrm{~mm}$, the curve of the $\dot{Y}$ with $\Delta l$ of $-5 \mathrm{~mm}$ is sharper which means the change of velocity is faster. It can be seen from the acceleration curves in Figure 13 (c) that with $\Delta l$ decreasing from -5 to $-15 \mathrm{~mm}$, the positive maximum of the acceleration $\ddot{Y}$ decreases from 31.9 to $26.0 \mathrm{~m} \mathrm{~s}^{-2}$ while the negative maximum value decreases from the absolute value of 67.6 to $38.8 \mathrm{~m} \mathrm{~s}^{-2}$. The positive maximum acceleration corresponds to the valley of the wave in Figure 13(a) where the screen surface is in a relaxed state.
On the contrary, the negative maximum acceleration corresponds to the wave peak of the deflection $Y$, where the screen surface is relatively tensioned. The vibration of the screen surface will be more intense under the state of tension. Therefore, the negative maximum acceleration is greater than the positive maximum acceleration.

During the screening process of the FFSCLS, slight vibration of the screen surface is not conducive to the movement of the material particles, and the looseness and layering of the material layer are adversely affected. Thus, the decrease of $\Delta l$ affects the screening efficiency detrimentally.

However, it can be expected that the surface will vibrate more violently when the tension length $\Delta l$ continues to increase. Figure 14(a) shows the vibration characteristics of the surface midpoint at the tension length $\Delta l$ of -1 and $-0.2 \mathrm{~mm}$ under eccentricity $e$ of $8 \mathrm{~mm}$. Numerical singularity of acceleration $\ddot{Y}$ (exceeds $15 \mathrm{~g}$ with $\Delta l$ of $-1 \mathrm{~mm}$ and exceeds $30 \mathrm{~g}$ with $\Delta l$ of $-0.2 \mathrm{~mm}$ ) can be found when the screen surface vibrated periodically. The acceleration $\ddot{Y}$ even exceeds $22 \mathrm{~g}$ with $\Delta l$ of $-1 \mathrm{~mm}$ and exceeds $50 \mathrm{~g}$ with $\Delta l$ of $-0.2 \mathrm{~mm}$ under eccentricity $e$ of $12 \mathrm{~mm}$, as shown in Figure 14(b). Under exaggerated stretch conditions of $\Delta l>0$ which mean the relative position between the two ends of the surface $L$ exceeds the free length of the screen surface $l$, the surface profile is a straight line and cannot be modelled as a three-tangent arcs theory. Besides, the high acceleration is beneficial to self-cleaning when the surface is exaggeratedly stretched, but exaggerated stretch may decrease the lifetime of the screen surface. Therefore, $\Delta l$ should be within a reasonable range of -15 to $-5 \mathrm{~mm}$.

\section{Conclusions}

In this work, the vibration characteristics of an industrialscale flip-flow screen with crank-link structure (FFSCLS) were studied. Based on the current investigation, the following conclusions are drawn: 
(1) The vibration characteristics of the floating box, the fixed box, and the midpoint of the screen surface could be calculated based on the proposed kinematic model of FFSCLS. The corresponding experimental results could be obtained based on the vibration test system. The maximum accuracy between the theoretical and the experimental results was 93.04\% which proved high validity and accuracy of the kinematic model.

(2) The kinematic characteristics of the screen surface along the $X$-direction are determined by the relative vibration of the floating box and fixed box. The vibration of the floating box and fixed box becomes more intense with the increase of the crackshaft eccentricity $e$ and the crackshaft rotational speed $\omega$ of the crankshaft. The vibration characteristics of the screen surface midpoint along with the $Y$-direction increase with the increase of the tension length $\Delta l$. A reasonable screening status of the flip-flow screen could be obtained when the parameters of $e, \omega$, and $\Delta l$ were within $6 \mathrm{~mm}$ to $12 \mathrm{~mm}, 51.8 \mathrm{rads}^{-1}$ to $64.2 \mathrm{rads}^{-1}$, and $-15 \mathrm{~mm}$ to $-5 \mathrm{~mm}$, respectively.

\section{Data Availability}

The raw data required to reproduce these findings cannot be shared at this time, as the data also form part of an ongoing study.

\section{Conflicts of Interest}

The authors declare that they have no conflicts of interest.

\section{Acknowledgments}

This work was financially supported by the National Natural Science Foundation of China (Grant nos. 51775544, 52075535, and U1508210), the Natural Science Foundation of Jiangsu (Grant no. BK20170288), and the Priority Academic Program Development of Jiangsu Higher Education Institutions.

\section{References}

[1] Y. Zhao, G. Li, Z. Luo et al., "Industrial application of a modularized dry-coal-beneficiation technique based on a novel air dense medium fluidized bed," International Journal of Coal Preparation and Utilization, vol. 37, no. 1, pp. 44-57, 2017.

[2] V. P. Barbosa, A. L. Menezes, R. Gedraite, and C. H. Ataíde, "Vibration screening: a detailed study using image analysis techniques to characterize the bed behavior in solid-liquid separation," Minerals Engineering, vol. 154, Article ID 106383, 2020.

[3] F. S. Guerreiro, R. Gedraite, and C. H. Ataíde, "Residual moisture content and separation efficiency optimization in pilot-scale vibrating screen," Powder Technology, vol. 287, pp. 301-307, 2016.

[4] P. Zhao, Y. Zhao, Z. Chen, and Z. Luo, "Dry cleaning of fine lignite in a vibrated gas-fluidized bed: segregation characteristics," Fuel, vol. 142, pp. 274-282, 2015.
[5] C. Yu, X. W. Wang, K. F. Pang, G. F. Zhao, and W. P. Sun, "Dynamic Characteristics of a Vibrating Flip-Flow Screen and Analysis for Screening $3 \mathrm{~mm}$ Iron Ore," Shock and Vibration, vol. 2020, 12 pages, 2020.

[6] H. Jiang, Y. Zhao, J. Qiao et al., "Process analysis and operational parameter optimization of a variable amplitude screen for coal classification," Fuel, vol. 194, pp. 329-338, 2017.

[7] K. Liu, "Some factors affecting sieving performance and efficiency," Powder Technology, vol. 193, no. 2, pp. 208-213, 2009.

[8] A. Noble and G. H. Luttrell, "A review of state-of-the-art processing operations in coal preparation," International Journal of Mining Science and Technology, vol. 25, no. 4, pp. 511-521, 2015.

[9] O. A. Makinde, B. I. Ramatsetse, and K. Mpofu, "Review of vibrating screen development trends: linking the past and the future in mining machinery industries," International Journal of Mineral Processing, vol. 145, pp. 17-22, 2015.

[10] G. Zheng, J. Zhu, W. Xia, and S. Liu, "Banana flip-flow screen benefits coal preparation," Filtration + Separation, vol. 53, pp. 38-41, 2016.

[11] M. Jahani, A. Farzanegan, and M. Noaparast, "Investigation of screening performance of banana screens using LIGGGHTS DEM solver," Powder Technology, vol. 283, pp. 32-47, 2015.

[12] L. Huang, Y. Zhao, H. Jiang et al., "Multi-parameter optimization of rigid-flexible coupled elastic rod screening for moist coal," Powder Technology, vol. 360, pp. 1200-1209, 2020.

[13] Q. Guo and G. Gong, Application of Flip Flow Screen in Sihe Coal Preparation Plant, pp. 913-918, Springer International Publishing, New York, NY, USA, 2016.

[14] D. P. Mishra and S. K. Das, "Application of polymeric flocculant for enhancing settling of the pond ash particles and water drainage from hydraulically stowed pond ash," International Journal of Mining Science and Technology, vol. 23, no. 1, pp. 21-26, 2013.

[15] H. Akbari, L. Ackah, and M. Mohanty, "Performance optimization of a new air table and flip-flow screen for fine particle dry separation," International Journal of Coal Preparation and Utilization, vol. 40, no. 9, pp. 581-603, 2020.

[16] X. Xiong, L. Niu, C. Gu, and Y. Wang, "Vibration characteristics of an inclined flip-flow screen panel in banana flipflow screens," Journal of Sound and Vibration, vol. 411, pp. 108-128, 2017.

[17] M. Pan, C. Duan, L. Tang et al., "Kinematics of a novel screen surface and parameter optimization for steam coal classification," Powder Technology, vol. 364, pp. 382-391, 2020.

[18] J. Tang, L. Niu, X. Xiong, and S. Jie, "Viscoelasticity of rubber springs affects vibration characteristics of a flip-flow screen with the high G value," IEEE Access, vol. 8, pp. 26950-26965, 2020.

[19] W. Zhao, Dynamic Characteristics Analysis and Optimized Design of 3080 Circular Vibration Flip-Flow Screen, , Ph.M. thesis, China University of Mining and Technoligy, 2019.

[20] S. Andree and P. Pavel, Improved Screening of Coal and Other Difficult to Screen Bulk Materials by Means of LIWELL Screens, Springer International Publishing, New York, NY, USA, 2016.

[21] H. Zhai, "Integral optimization of systematic parameters of flip-flow screens," Journal of China University of Mining \& Technology, vol. 14, pp. 78-82, 2004.

[22] J. Zhang, Y. Huang, and Z. Chen, "The basic dynamics study of Flip-Flow Screen and particles based on MATLAB," 
Advances in Computational Modeling and Simulation, and 22014, vol. 2796, pp. 1340-1344, 2013.

[23] L. Peng, F. Li, H. Dong, C. Liu, Y. Zhao, and C. Duan, "Characteristics analysis of a novel centralized-driving flipflow screen," International Journal of Mining Science and Technology, vol. 24, no. 2, pp. 195-200, 2014.

[24] B. Wu, X. Zhang, L. Niu, X. Xiong, Z. Dong, and J. Tang, "Research on sieving performance of flip-flow screen using two-way particles-screen panels coupling strategy," IEEE Access, vol. 7, pp. 124461-124473, 2019.

[25] Z. Zhang and Y. Wang, "Deformation analysis of polyurethane screen deck in linear vibrating screen," Advanced Polymer Science and Engineering, vol. 1159, pp. 240-246, 2011.

[26] S. Baragetti and F. Villa, "A dynamic optimization theoretical method for heavy loaded vibrating screens," Nonlinear Dynamics, vol. 78, no. 1, pp. 609-627, 2014.

[27] Z. R. Zhang, Y. Y. Wang, and Z. M. Fan, "Similarity Analysis between Scale Model and Prototype of Large Vibrating Screen," Shock andVibration, vol. 2015, Article ID 247193, 7 pages, 2015.

[28] E. Zhou, G. Yan, X. Weng, Z. Zhang, P. Zhao, and B. Zhang, "A novel and low cost coal separation process: combination of deep screening classification and gravity separation," Powder Technology, vol. 367, pp. 568-575, 2020.

[29] S. P. Gong, S. Oberst, and X. W. Wang, "An experimentally validated rubber shear spring model for vibrating flip-flow screens," Inside MS, vol. 139, p. 15, 2020.

[30] Z. Mengqi, L. Chusheng, W. Jida, and W. Zhenqian, "Influence of tensional amount on dynamic parameters of unilateral driven flip-flow screen surface," Journal of China Coal Society, vol. 43, 2018. 